\title{
The Role of Costimulatory Receptors of the Tumour Necrosis Factor Receptor Family in Atherosclerosis
}

\author{
Ricardo F. Antunes, Juan Carlos Kaski, and Ingrid E. Dumitriu \\ Cardiac and Vascular Sciences, Division of Clinical Sciences, St. George's University of London, Cranmer Terrace, London, \\ SW17 ORE, UK \\ Correspondence should be addressed to Ingrid E. Dumitriu, i.dumitriu@sgul.ac.uk
}

Received 31 August 2011; Accepted 11 October 2011

Academic Editor: Byoung S. Kwon

Copyright ( $\odot 2012$ Ricardo F. Antunes et al. This is an open access article distributed under the Creative Commons Attribution License, which permits unrestricted use, distribution, and reproduction in any medium, provided the original work is properly cited.

\begin{abstract}
Atherosclerosis is a chronic inflammatory disease that is mediated by both the innate and adaptive immune responses. $\mathrm{T}$ lymphocytes, that together with B cells are the cellular effectors of the adaptive immune system, are currently endowed with crucial roles in the development and progression of atherosclerosis. Costimulatory receptors are a class of molecules expressed by $\mathrm{T}$ lymphocytes that regulate the activation of $\mathrm{T}$ cells and the generation of effector $\mathrm{T}$-cell responses. In this review we present the roles of costimulatory receptors of the tumour necrosis factor receptor (TNFR) superfamily in atherosclerosis and discuss the implications for future therapies that could be used to specifically modulate the immune response of pathogenic $\mathrm{T}$ cells in this disease.
\end{abstract}

\section{Introduction}

Atherosclerosis is a disease of large and medium-sized arteries, characterized by focal thickening of the innermost layer of the arterial wall, the intima, due to accumulation of lipids. Initially, it was thought that the main pathogenic mechanism was deposition of lipids (mainly low density lipoprotein, LDL) in the vessel wall. However, evidence from several studies on animal models and the human disease showed that atherosclerosis is predominantly a chronic inflammatory disorder that involves various cells of the innate and adaptive arms of the immune system (reviewed in $[1,2]$ ). The first insight on the contribution of the adaptive immune system to atherogenesis that was at the time mainly regarded as a disease mediated exclusively by innate immune cells such as macrophages, came with the identification of $\mathrm{T}$ cells in human atherosclerotic plaques $[3,4]$. Moreover, detection of T-cell-dependent antibodies directed against oxidised LDL (oxLDL) in patients with atherosclerosis [5] provided further support to the view that $\mathrm{T}$ cells actively mediate atherogenesis. It is now well accepted that the main cellular components of the adaptive immune system, $\mathrm{T}$ and $\mathrm{B}$ lymphocytes, have important effects not only on the development of atheroscle- rotic plaques but also in the processes that lead to plaque rupture [6].

T-cell-mediated adaptive immune responses are triggered by recognition of antigen (derived from pathogens) on antigen presenting cells (APCs) such as dendritic cells (DCs) and macrophages. However, optimal activation of $\mathrm{T}$ cells and generation of effector/memory responses requires more than just antigen recognition and is tightly dependent on costimulatory signals. These are delivered by costimulatory receptors expressed on T lymphocytes following interaction with their ligands on APCs [7]. The expression of costimulatory ligands on APCs is often triggered or upregulated by infection or cell damage and therefore is designed to elicit immune responses only when required, limiting the chance for unwanted responses. Due to their central roles in modulation of T-cell responses, costimulatory receptors and their ligands represent a promising target for the treatment of diseases associated with chronic inflammation (autoimmunity, organ transplantation, and cancer). Currently, a great deal of effort is concentrated on designing therapeutic tools (neutralising antibodies, agonistic antibodies, immunoglobulin fusion proteins, etc.) that will enable targeted manipulation of costimulatory pathways in pathogenic T cells. A family of 
costimulatory receptors that has captured the attention of the scientific community as a particularly promising target for immunemodulation is the tumour necrosis factor receptor (TNFR) superfamily. Several members of this family with costimulatory function have been shown to contribute to the immune response underlying atherosclerosis. Here, we discuss the roles of TNFR costimulatory receptors in atherosclerosis and highlight therapeutic strategies to modulate these molecules that could soon find their way into the clinic to tackle this disease.

\section{2. $\mathrm{T}$ Cells in Atherosclerosis}

In addition to the key roles played by cells of the innate immune system (i.e., macrophages, dendritic cells (DCs), mast cells, and neutrophils) in atherogenesis (recently reviewed $[1,8]), \mathrm{T}$ and $\mathrm{B}$ lymphocytes, which are the main mediators of adaptive immunity, have also important contributions [9]. Indeed, $\mathrm{T}$ cells have been consistently found in atherosclerotic lesions, accounting for almost $20 \%$ of the cells in the shoulder region of a plaque, and activated $\mathrm{T}$ cells are significantly increased in culprit lesions of patients with acute coronary syndrome (ACS) $[3,4]$. Furthermore, T cells from atherosclerotic plaques were shown to have an activated phenotype $[10,11]$ and to be involved in all stages of atherogenesis [12]. The current view is that $\mathrm{T}$ cells aggravate atherosclerosis by triggering inflammatory immune responses and contribute to the growth and rupture of atherosclerotic plaques.

A large number of studies on animal models that provide mechanistic insight in atherogenesis have shown that $\mathrm{CD} 4^{+} \mathrm{T}$ cells, and to a lesser extent $\mathrm{CD} 8^{+} \mathrm{T}$ cells, have active roles in this disease [13]. Indeed, the majority of $\mathrm{T}$ cells present in atherosclerotic plaques are $\mathrm{CD} 4^{+} \mathrm{T}$ cells [14]. Moreover, an elegant study performed by Zhou and colleagues demonstrated that the adoptive transfer of $\mathrm{CD}^{+} \mathrm{T}$ cells in $\mathrm{Apoe}^{-/-}$mice had proatherogenic effects [15]. While the role of $\mathrm{CD} 4^{+} \mathrm{T}$ cells in atherogenesis and plaque destabilization is now widely accepted, the complex dynamics of the different $\mathrm{CD} 4^{+} \mathrm{T}$ cells subsets and their contribution to atherogenesis is far from being understood. The main subsets of $\mathrm{CD}^{+} \mathrm{T}$ cells consist of $\mathrm{T}$ helper 1 (Th1) identified by their ability to secrete the proinflammatory cytokine interferon- $\gamma$ (IFN- $\gamma)$; Th2 cells that produce mainly interleukin-4 (IL-4); Th17 cells with IL-17 as their signature cytokine; regulatory $\mathrm{T}$ (Treg) cells that have important roles in suppression of immune responses and tolerance. Th1 cells have mainly proatherogenic effects, while the Th2 and Treg cell subsets have protective roles in atherosclerosis (reviewed in [9]). The contribution of the Th17 subset is not clear, as controversial results have suggested both pro- and antiatherogenic roles [16-18]. It is also possible that each Tcell subset and their products (i.e., cytokines) have different roles depending on the stage of atherosclerosis.

Several lines of evidence suggest that $\mathrm{T}$ cells are activated in atherosclerosis $[10,11]$, however the precise mechanisms responsible for this phenomenon remain largely unknown. The antigens that trigger the activation and expansion of $\mathrm{T}$ cells in atherosclerosis have not been fully characterized so far. Various infectious agents have been implicated as T cells that recognise antigens derived from Chlamydia pneumoniae, Herpes simplex, Helicobacter pylori, and Cytomegalovirus have been identified in the atherosclerotic lesions and peripheral circulation of patients with atherosclerosis [19]. In addition to these exogenous triggers, antigens from endogenous sources (such as oxLDL and human heat shock proteins, HSPs) have also been described in atherosclerosis [20, 21]. The expression of these antigens is very prominent in atherosclerotic lesions and correlates with the severity of the disease $[22,23]$. Another aspect of the immune response in atherosclerosis that is not completely understood is the site of antigen presentation and lymphocyte activation, which could either take place locally in the plaque or in the regional lymph nodes [3]. A study done by Rekhter and Gordon found that $\mathrm{T}$ cells proliferate in the atherosclerotic plaques, while a similar expansion could not be detected in the peripheral circulating compartment, suggesting a localized immune response within the plaques where recruitment, local activation, and generation of effector and memory $\mathrm{T}$ cells takes place [11]. Moreover, both antigen-dependent and antigenindependent (e.g., coreceptors and cytokines like IL-7 and IL-15) pathways may contribute to oligoclonal expansion of $\mathrm{T}$ cells in atherosclerotic plaques [24]. All these uncertainties regarding the antigens that elicit and drive the immune response in atherosclerosis hinder the design of therapeutic protocols that could slow down the progression of this disease. As costimulatory signals are crucial for the activation of $\mathrm{T}$ cells (either in the naive or effector/memory stage) and the function of effector T lymphocytes, modulation of costimulatory pathways could provide an alternative strategy to modulate the immune response in atherosclerosis.

\section{Effects of Costimulation in T Cells}

As mentioned in the introduction, T-cell activation is triggered by antigen recognition on APC (e.g., DCs and macrophages). This process takes place in the secondary lymphoid organs (lymph nodes or spleen) and leads to the activation of T lymphocytes and their proliferation and differentiation into effector T cells. Some of these effector T cells will migrate into the inflamed/infected tissues and tackle the pathogens themselves or deliver signals required for the activation of macrophages (and other cells of the innate immune system) so that they can efficiently clear the infection. In addition, certain subsets of effector $\mathrm{T}$ cells deliver signals that direct the production of antibodies by B cells. A small population of memory $\mathrm{T}$ cells are also induced following antigen recognition, and these cells are responsible for the quick and effective clearance of pathogens following subsequent contact with the same pathogen (i.e., recall immune responses). In the case of naive $\mathrm{T}$ cells, antigen recognition is not sufficient for the activation of $\mathrm{T}$ cells, and a second signal, called the costimulatory signal, is required [7]. This second signal is delivered following interaction of costimulatory receptors expressed on $\mathrm{T}$ cells with their ligands (i.e., costimulatory molecules) expressed on APCs. Costimulation is neither antigen specific nor MHC dependent and is involved in the bidirectional signalling in and out of $\mathrm{T}$ cells [7]. Costimulatory signals are critical to allow full activation of naive 
$\mathrm{T}$ cells and their differentiation into effector and/or memory $\mathrm{T}$ cells. Moreover, Costimulation is critical for the survival of $\mathrm{T}$ cells by preventing apoptosis and/or anergy and for the production of cytokines by effector $\mathrm{T}$ lymphocytes [7]. In addition, cooperation between $\mathrm{T}$ cells and other cells of the immune system (such as B lymphocytes, DCs, and macrophages) is also tightly regulated by interaction between costimulatory receptors and ligands [25]. In addition to costimulatory signals, the differentiation of $\mathrm{CD} 4^{+} \mathrm{T}$ lymphocytes into various effector cells is regulated by cytokines present in the microenvironment at the moment of T-cell activation (i.e., signal three). The generation of Th1 cells is controlled by IL-12 that is secreted by mature DCs and activated macrophages upon interaction with microbial products [26]. IL-4 is the main cytokine that drives differentiation into the Th2 lineage [27]. With regard to the cytokines that regulate the generation of Th17 cells some debate still exists, with IL-6 being a definite requirement, while the contribution of transforming growth factor- $\beta$ (TGF- $\beta$ ) has been questioned by some studies [28-30]. Some of the cytokines that deliver signal three for effector T-cell differentiation have been implicated in atherosclerosis (recently reviewed in [31]).

The first identified costimulatory receptor is CD28 that is constitutively expressed on naive $\mathrm{T}$ cells and promotes T-cell activation [7]. In the absence of signals via CD28, naive $\mathrm{T}$ cells fail to get activated and enter a state of anergy. Engagement of CD28 by its ligands B7.1 (CD80) and B7.2 (CD86) lowers the activation threshold of $\mathrm{T}$ cells and provides key stimulatory signals to allow high-level IL-2 production and survival of naive $\mathrm{T}$ cells [32]. Activated T cells express additional costimulatory receptors to $\mathrm{CD} 28$, some of which sustain T-cell activation (e.g., ICOS, inducible costimulator; OX40; 4-1BB), and others, with inhibitory effects (e.g., CTLA-4, cytotoxic T lymphocyte antigen-4; and PD-1, programmed death-1) [32-35]. The coinhibitory receptors have critical roles in limiting the activation and expansion of $\mathrm{T}$ cells and prevent the development of pathological immune responses by induction and maintenance of T-cell tolerance [36]. An optimal balance between costimulatory and coinhibitory receptors is critical for an adequate and wellbalanced T-cell response following encounter with pathogens. Based on their structure, costimulatory receptors have been grouped in two main families: the immunoglobulin (Ig) superfamily (which includes CD28, CTLA-4, and PD-1) and the tumour necrosis factor receptor (TNFR) family, including OX40, 4-1BB, and others, which will be discussed in the next section.

\section{Costimulatory Receptors of the TNFR Family}

TNFR/TNF ligand superfamily has several members that are involved in Costimulation of $\mathrm{T}$ cells: CD40/CD40L, OX40/OX40L, 4-1BB/4-1BBL, CD27/CD70, CD30/CD30L, HVEM/LIGHT, and GITR/GITRL $[35,37]$. In contrast to CD28, which is constitutively expressed by naive $\mathrm{T}$ cells, the expression of most of the costimulatory receptors of TNFR family is only induced following T-cell activation, hours to days after antigen recognition [25]. These receptors provide signals that promote the expansion and survival of $\mathrm{T}$ cells to amplify and sustain the longevity of T-cell-mediated immune responses and to enhance the generation of effector and memory $\mathrm{T}$ cells both in primary and recall immune responses [25]. In addition, signals via TNFR costimulatory receptors increase the production of cytokines by effector T cells. The majority of TNFR costimulatory receptors lack intrinsic signalling activity and thereby need to recruit intracellular adaptor molecules called TNFR-associated factors (TRAFs) to trigger intracellular signalling pathways [35]. Six mammalian TRAF proteins have been identified so far (TRAF1-6), which have been shown to interact directly or indirectly with the intracellular domains of the TNFR [38]. TRAF proteins have a conserved 180 amino acid fold, the TRAF domain (TD), which promotes the interaction between TNFRs and their downstream signalling intermediates. The C-terminus of the TD mediates homo- and heterodimerization with other TRAF proteins and the receptor that recruits them. The cytosolic region of TNFR contains motifs 4-6 amino acids long that regulate the interaction with TRAFs [39]. TNFR ligation leads to TRAF aggregation and subsequent activation of downstream protein kinase cascades. Several TRAFs can trigger the activation of nuclear factor- $\kappa \mathrm{B}(\mathrm{NF}-\kappa \mathrm{B})$ by interacting with the inhibitor of NF- $\kappa \mathrm{B}$ (I $\kappa \mathrm{B})$ subunits [40]. NF- $\kappa \mathrm{B}$ signalling promotes cell survival by regulation of apoptosis pathways. Costimulatory signals delivered by TNF/TRAF interactions promote the proliferation of $\mathrm{T}$ cells by enabling progression through the cell cycle [41]. In addition, TRAF members activate mitogen-activated protein (MAP) kinase signalling that is important for the production of proinflammatory cytokines by $\mathrm{T}$ lymphocytes [42]. It is likely that structural differences between various TRAF members determine the signalling pathways that will be triggered and the ultimate cellular effects [35]. We next discuss the contribution of various TNFR costimulatory receptors to atherosclerosis.

\section{CD40 and CD40L}

CD40L (also known as CD154) was originally identified on activated $\mathrm{T}$ cells, while CD40 is expressed by APCs [43, 44] (Table 1). Costimulatory signals delivered by the CD40/ CD40L pair are crucial for optimal APC activation and production of inflammatory cytokines. In addition, they also promote the activation of $\mathrm{T}$ cells by increasing the expression of costimulatory ligands on APCs $[43,44]$. Furthermore, as B cells constitutively express CD40, interaction with CD40L on activated $\mathrm{T}$ cells is crucial for the development of humoral immune responses regulating the proliferation of B lymphocytes and the production of antibodies, isotype switching, and generation of memory B cells [45]. In addition to these roles in regulation of adaptive immune responses and inflammation, CD40/CD40L interaction enhances angiogenesis. CD40 ligation with soluble CD40L (sCD40L) triggered production of vascular endothelial growth factor (VEGF) from endothelial cells and monocytes and promoted angiogenesis [46]. Another study demonstrated that endothelial cells treated with anti-CD40L antibodies to ligate CD40 produced several angiogenic factors (including VEGF and 
TABLE 1: Expression and key features of costimulatory TNFR family members in T cells.

\begin{tabular}{|c|c|c|c|c|}
\hline Receptor/ligand & Receptor distribution & Ligand distribution & Main effects on T cells & Ref. \\
\hline CD40/CD40L & $\begin{array}{l}\text { APCs (DCs, B cells, } \\
\text { macrophages) }\end{array}$ & $\begin{array}{l}\text { Activated T cells } \\
\text { Activated DCs }\end{array}$ & $\begin{array}{l}\text { Promotes T-cell activation by increasing costimulatory } \\
\text { ligands on APCs }\end{array}$ & {$[43,44]$} \\
\hline OX40/OX40L & $\begin{array}{l}\text { Activated T cells } \\
\text { Treg cells } \\
\text { NK cells } \\
\text { NKT cells } \\
\text { Neutrophils }\end{array}$ & $\begin{array}{l}\text { APCs (DCs, B cells, } \\
\text { and macrophages) } \\
\text { Activated T cells } \\
\text { NK cells } \\
\text { Activated endothelial } \\
\text { cells } \\
\text { Smooth muscle cells } \\
\text { Mast cells }\end{array}$ & $\begin{array}{l}\text { Prolongs T-cell clonal expansion } \\
\text { Increases production of cytokines from effector T cells } \\
\text { Promotes the survival of activated T cells } \\
\text { Inhibits the development and suppressive function of } \\
\text { Treg cells (?) }\end{array}$ & {$[70,71]$} \\
\hline $4-1 \mathrm{BB} / 4-1 \mathrm{BBL}$ & $\begin{array}{l}\text { Activated T cells } \\
\text { Monocytes } \\
\text { DCs } \\
\text { NK cells } \\
\text { NKT cells } \\
\text { Neutrophils } \\
\text { Endothelial cells }\end{array}$ & $\begin{array}{l}\text { APCs (DCs, B cells, } \\
\text { and macrophages) } \\
\text { Activated T cells }\end{array}$ & $\begin{array}{l}\text { Promotes the activation, survival, and function of } \\
\text { effector T cells }\end{array}$ & {$[94]$} \\
\hline CD27/CD70 & $\begin{array}{l}\text { Naive T cells } \\
\text { Thymocytes } \\
\text { Memory B cells } \\
\text { NK cells }\end{array}$ & $\begin{array}{l}\text { APCs (DCs and B } \\
\text { cells) } \\
\text { Activated T cells }\end{array}$ & $\begin{array}{l}\text { Regulates the generation of effector } \mathrm{T} \text { cells by } \\
\text { enhancing the proliferation and survival of activated } \mathrm{T} \\
\text { cells }\end{array}$ & {$[118,119]$} \\
\hline CD30/CD30L & $\begin{array}{l}\text { Activated T cells } \\
\text { B cells } \\
\text { NK cells } \\
\text { Eosinophils }\end{array}$ & $\begin{array}{l}\text { B cells } \\
\text { Activated T cells }\end{array}$ & $\begin{array}{l}\text { Increases proliferation and cytokine production of } \mathrm{T} \\
\text { cells }\end{array}$ & {$[128-130]$} \\
\hline HVEM/LIGHT & $\begin{array}{l}\text { Resting T cells } \\
\text { DCs } \\
\text { Monocytes }\end{array}$ & $\begin{array}{l}\text { Monocytes } \\
\text { Immature DCs } \\
\text { Activated T cells } \\
\text { NK cells }\end{array}$ & Promotes T-cell activation and cytokine production & {$[134,135]$} \\
\hline GITR/GITRL & $\begin{array}{l}\text { Resting and activated } \\
\mathrm{T} \text { cells } \\
\text { Constitutive } \\
\text { Expression in Treg } \\
\text { cells }\end{array}$ & $\begin{array}{l}\text { APCs (DCs, B cells, } \\
\text { and macrophages) }\end{array}$ & $\begin{array}{l}\text { Enhances the proliferation and survival of activated T } \\
\text { cells } \\
\text { Potentiates the production of cytokines from effector T } \\
\text { cells } \\
\text { Role in suppressive function of Treg cells }\end{array}$ & $\begin{array}{c}{[98,139,141} \\
142]\end{array}$ \\
\hline
\end{tabular}

fibroblast growth factor 2). Furthermore, administration of CD40L-expressing cells dramatically enhanced angiogenesis in human skin grafts transplanted in immunodeficient SCID mice [47]. In addition, the CD40/CD40L system and the adaptor molecule TRAF6 are also involved in neointima formation and arterial remodelling [48]. These results suggest that CD40-CD40L interactions have crucial roles in mediating inflammation and angiogenesis and could therefore contribute to the development and progression of atherosclerotic plaques.

Several cells within atherosclerotic plaques such as endothelial cells, macrophages, vascular smooth muscle cells, and T lymphocytes express CD40 and CD40L $[49,50]$. Of note, platelets express CD40 constitutively, and CD40L is induced on activated platelets [51]. Interaction of CD40L on activated $\mathrm{T}$ cells with CD40 in the plaque microenvironment is thought to contribute to secretion of inflammatory cytokines and matrix metalloproteinases from macrophages and to enhance the expression of adhesion molecules on endothelial cells [52]. Further proof that CD40 and CD40L contribute to atherosclerosis comes from studies that have targeted these molecules in murine models of the disease (Table 2). Administration of a neutralising antibody against CD40 to $\mathrm{Ldlr}^{-1-}$ mice reduced the size and lipid content of atherosclerotic lesions [53]. In addition, the macrophage and T-cell infiltrate was dramatically reduced in atherosclerotic plaques from mice treated with anti-CD40 antibodies. Another study targeted signalling via CD40L and found that deletion of CD40L in Apoe $e^{-/-}$mice ( $c d 40 l^{-/-} A p o e^{-/-}$mice) resulted in decreased plaque size and reduced numbers of $\mathrm{T}$ cells and macrophages in atherosclerotic lesions compared to $A p o e^{-/-}$mice [54]. Similarly, Schönbeck et al. found that the CD40/CD40L pathway not only influences the initial stages of atherosclerosis development but has also an effect in advanced disease. The authors showed that treatment with anti-CD40L antibodies reduced the progression of already established atherosclerotic plaques in $\mathrm{Ldlr}^{-/-}$mice [55]. An interesting finding was that blockade of CD40/CD40L signalling resulted in atherosclerotic plaques with a more stable phenotype, characterized by low numbers of $\mathrm{T}$ lymphocytes and macrophages, suggesting that the CD40/CD40L axis has important roles in plaque 
TABLE 2: TNF superfamily members and their role in atherosclerosis.

\begin{tabular}{|c|c|c|c|}
\hline Receptor/ligand pair & Experimental model & Role in atherosclerosis & Ref. \\
\hline \multirow[t]{2}{*}{ CD40/CD40L } & Animal models & $\begin{array}{l}\text { Mainly proatherogenic effects (demonstrated by } \\
\text { administration of neutralising antibodies to CD40; } \\
\text { deletion of CD } 40 \mathrm{~L} \text { ) }\end{array}$ & [53-55] \\
\hline & Human atherosclerosis & $\begin{array}{l}\text { CD } 40 \text { and CD } 40 \mathrm{~L} \text { are expressed in atherosclerotic } \\
\text { plaques } \\
\text { Increased levels of serum sCD } 40 \mathrm{~L} \text { in unstable angina; } \\
\text { correlate with poor prognosis } \\
\text { Polymorphisms in the CD } 40 \text { gene associate with } \\
\text { unstable plaques and increased risk of ACS }\end{array}$ & {$[49,61,62]$} \\
\hline \multirow[t]{2}{*}{ OX40/OX40L } & Animal models & $\begin{array}{l}\text { Mainly proatherogenic effects (demonstrated by } \\
\text { targeted deletion of OX40; administration of } \\
\text { neutralising antibodies to OX40L). }\end{array}$ & \\
\hline & Human atherosclerosis & $\begin{array}{l}\text { Polymorphisms in the genes for OX } 40 \text { or OX } 40 \mathrm{~L} \\
\text { associate with myocardial infarction and CAD severity; } \\
\text { OX } 40 \text { and OX40L upregulated in atherosclerotic tissue } \\
\text { or circulating immune cells; sOX40L serum levels } \\
\text { increased in ACS patients and associated with higher } \\
\text { risk of AMI }\end{array}$ & {$[83,88,90]$} \\
\hline \multirow[t]{2}{*}{$4-1 \mathrm{BB} / 4-1 \mathrm{BBL}$} & Animal models & $\begin{array}{l}\text { Promotes atherogenesis (demonstrated by } \\
\text { administration of agonist antibody anti-4-1BB; } \\
\text { deletion of } 4-1 \mathrm{BB}) \text {. }\end{array}$ & {$[104,107,108]$} \\
\hline & Human atherosclerosis & $\begin{array}{l}\text { 4-1BB is expressed in atherosclerotic plaques; increased } \\
\text { levels on circulating immune cells; serum levels of } \\
\text { s4-1BB increased in ACS patients }\end{array}$ & {$[109,110]$} \\
\hline $\mathrm{CD} 27 / \mathrm{CD} 70$ & Human atherosclerosis & $\begin{array}{l}\text { CD27 and CD70 are present in atherosclerotic plaques. } \\
\text { CD27 }{ }^{+} \text {Treg cell subtype levels decreased in patients } \\
\text { with myocardial infarction }\end{array}$ & {$[122-124]$} \\
\hline CD30/CD30L & Human atherosclerosis & Just one study available with inconclusive results & {$[170]$} \\
\hline HVEM/LIGHT & Human atherosclerosis & $\begin{array}{l}\text { HVEM and LIGHT detected in atherosclerotic plaques. } \\
\text { Elevated plasma levels of LIGHT in plasma of unstable } \\
\text { angina and ischemic (atherosclerotic) stroke patients }\end{array}$ & {$[148-151]$} \\
\hline GITR/GITRL & Human atherosclerosis & $\begin{array}{l}\text { GITR and GITRL present in atherosclerotic plaques. } \\
\text { Decreased numbers of GITR }{ }^{+} \text {Treg cells in } \\
\text { atherosclerotic lesions }\end{array}$ & {$[152,153]$} \\
\hline
\end{tabular}

destabilisation [53-55]. A recent study which found that the proatherogenic effects of CD40L are independent of CD40 as $\mathrm{Ldlr} \mathrm{r}^{-1-}$ mice that were also deficient in CD40 ( $c d 40^{-1-} \mathrm{Ldlr}^{-1-}$ mice) showed no reduction in the formation of atherosclerotic plaques compared to $L d l r^{-/-}$mice [56]. Furthermore, they proposed that CD40L effects are mediated by interaction with Mac-1 (CD11b/CD18), an integrin receptor expressed on monocytes and macrophages [56]. These results clearly indicate that CD40/CD40L signalling contributes to atherogenesis in murine models of the disease, although the precise cell subsets that are involved in these effects are not completely defined. Indeed, some authors proposed that CD40L expression on nonhaematopoietic cells is important in atherogenesis [57, 58]. Bavendiek et al. [57] found no differences in the size and cellular composition of atherosclerotic plaques of irradiated $\mathrm{Ldlr}^{-/-}$mice that were reconstituted with bone marrow from either $\mathrm{Ldlr}^{-/-}$mice or $L d l r^{-/-} c d 40 l^{-/-}$double deficient mice. Another study with similar findings demonstrated that reconstitution of irradiated $\mathrm{Ldll}^{-/-}$mice with $c d 40 \mathrm{l}^{-/-}$bone marrow had no effect on the progression and phenotype of atherosclerotic lesions when compared to wild type bone marrow [58]. It cannot be excluded that, in the animal models analysed, some of the antiatherogenic effects of CD40/CD40L costimulatory pathway blockade/deletion are mediated by alterations in the expression and/or function of other costimulatory receptors/ molecules [59]. Another possible way in which CD40/CD40L blockade could modulate atherogenesis is by changing the balance between activated effector $\mathrm{T}$ cells and regulatory $\mathrm{T}$ cells. In a transplantation model it was found that CD40/ CD40L blockade not only inhibited the function of effector $\mathrm{T}$ cells but also enhanced the suppressive function of $\mathrm{CD}^{+} \mathrm{CD} 25^{+}$Treg cells [60]. Whether CD40/CD40L blockade could alter the immuno-suppressive effects of Treg cells in atherosclerosis is not yet known.

Data from patients with atherosclerosis also suggest that CD40L contributes to the pathogenesis of ACS and has prognostic value (Table 2) $[61,62]$. The levels of sCD40L, which is released mainly from activated platelets and $\mathrm{T}$ lymphocytes, 
were elevated in the serum of unstable angina patients but not in stable angina and healthy subjects [61]. Furthermore, patients with unstable angina were found to have increased percentages of both $\mathrm{CD}^{+}$and $\mathrm{CD}^{+} \mathrm{T}$ cells when compared to stable angina patients and controls. As platelets have been shown to be the main source of circulating sCD40L, these cells could therefore account for most of the effects of sCD40L in atherogenesis [49]. Elevated sCD40L levels were an independent predictor of recurrent cardiovascular events after ACS and correlated with poor prognosis [62-64]. Of note, statins were found to dramatically downregulate sCD40L levels in patients with familial hypercholesterolemia [65]. Another indication that CD40 has proatherogenic effects is that polymorphisms in the CD40 gene were found to associate with the presence of unstable coronary atherosclerotic plaques and an increased risk of ACS $[66,67]$.

Given the important effects of CD40/CD40L signalling in atherosclerosis, therapeutic strategies that target this pathway were thought to be beneficial in modulating the inflammatory response in this disease. However, one obstacle to clinical applications of targeting CD40/CD40L is the broad expression of this receptor/ligand pair. In particular, constitutive expression of CD40 on platelets and upregulation of CD40L following platelet activation are responsible for platelet activation and thrombosis [68]. Indeed, CD40 blockade was found to have prothrombotic effects in humans that prevent it from being used $[49,69]$. Therefore, therapeutic strategies that allow specific targeting of CD40/CD40L on particular cell subsets (such as macrophages or T cells), but not on platelets, need to be developed for successful clinical applications in atherosclerosis.

\section{OX40 and OX40L}

The interaction between OX40 (also known as CD134) and OX40L is critical for optimal generation of effector T-cell responses [70-72]. Ligation of OX40 elicits signalling pathways that sustained T-cell responses by prolonging clonal expansion and enhanced cytokine secretion from effector $\mathrm{T}$ cells [73]. In addition, it upregulated the expression of antiapoptotic proteins of the Bcl-2 family (e.g., Bcl-2 and Bcl$\mathrm{xL}$ ) and, by doing so, promoted the survival of activated $\mathrm{T}$ lymphocytes [74]. Similar to other members of the TNFR family, OX40 is not expressed on resting $\mathrm{T}$ cells (Table 1), but can be induced both on $\mathrm{CD}^{+}$and $\mathrm{CD} 8^{+} \mathrm{T}$ cells after TCR/CD3 triggering, with its levels reaching a peak approximately 2-3 days following T-cell activation [70]. Moreover, effector/memory $\mathrm{T}$ cells rapidly reexpress OX40 after antigen reencounter [75]. Of note, the expression of OX40 is not restricted to conventional $\mathrm{T}$ cells as it was also found on Treg cells, natural killer (NK) cells, NKT cells, and neutrophils [76]. Recently, it has been shown that OX40/OX40L signals have different effects on effector T cells and Treg cells. While OX40 promoted the expansion of effector T cells, it blocked the development and inhibited the suppressive function of inducible Treg cells [77-80]. OX40L, the ligand for OX40, is expressed in a variety of cell types such as APCs (e.g., DCs, macrophages, B cells), activated endothelial cells and smooth muscle cells, NK cells, and mast cells $[81,82]$.
Importantly, activated T cells can also express OX40L [82], which could ligate OX40 on other $\mathrm{T}$ cells and therefore further amplify effector T-cell immune responses. Activated $\mathrm{T}$ cells expressing OX40 have been found at inflammatory sites in experimental models and clinical specimens in several inflammatory diseases, including rheumatoid arthritis $[25,37]$. Additionally, the levels of OX40 and OX40L are significantly higher in inflamed versus healthy tissues [72]. In addition to its costimulatory roles, OX40 is thought to regulate the $\mathrm{T}$-cell migration and tissue infiltration through its interaction with OX40L on endothelial cells [81].

Several studies support a role for OX40/OX40L interactions in atherosclerosis and coronary artery disease (CAD) (Table 2). In murine models of atherosclerosis, alterations in the OX40/OX40L axis had profound effects on disease development. Indeed, mice with targeted deletion of OX40L were found to have decreased atherosclerosis compared to control mice, while overexpression of OX40L increased the size of atherosclerotic plaques [83]. Moreover, administration of blocking antibodies to OX40L in $\mathrm{Ldlr}^{-/-}$mice reduced atherosclerosis [84]. This effect was attributed to inhibition of IL- 4 production from Th2 cells, which favoured the generation of protective IgM class anti-oxLDL antibodies and inhibited the production of proatherogenic IgG class antibodies. Another study demonstrated a reduction in atherosclerosis in double knock-out $A p o e^{-/-} / o x 40 l^{-/-}$mice compared to Apoe $e^{-/-}$mice [85]. The density of vasa vasorum was reduced in OX40L-deficient animals, which suggested that the OX40/OX40L system promotes the development of atherosclerosis, at least in part, through vasa vasorumdependent neovascularization [85]. As mentioned previously, OX40/OX40L costimulatory signals were also found to play a role in T-cell migration. Kotani et al. showed that OX40L ligation can induce the production of the CC chemokine RANTES/CCL5 from endothelial cells, which could mediate the adhesion and transmigration of $\mathrm{T}$ cells through the endothelium at inflammatory sites [86]. In allograft transplantation models, blockade of OX40/OX40L signalling was found to enhance the survival of corneal allografts [87], suggesting that targeting this pathway may provide a means to tackle inflammatory disorders.

In humans, polymorphisms in the genes for OX40 or OX40L were reported to associate with myocardial infarction and the severity of CAD $[83,88]$. In contrast, a recent study on patients with carotid endarterectomy failed to find any association between OX40L polymorphisms and the risk of ischemic stroke [89]. In this study, OX40L was upregulated in atherosclerotic lesions in comparison to control tissue and was found mainly on macrophages infiltrating human carotid atherosclerotic plaques. In further support of a role for OX40/OX40L interactions in atherosclerosis, a recent study described significantly higher expression of OX40 and OX40L on circulating CD4 ${ }^{+} \mathrm{T}$ cells from ACS patients, when compared to stable angina and controls [90]. We recently found that $\mathrm{CD} 4{ }^{+} \mathrm{CD} 28^{\text {null }} \mathrm{T}$ cells (a subset of $\mathrm{T}$ lymphocytes that increases in frequency in patients with ACS compared to stable angina and controls) had significantly higher levels of OX40 than conventional CD $4^{+} \mathrm{CD} 28^{+} \mathrm{T}$ lymphocytes [91]. Furthermore, inhibition of OX40 decreased the ability of 
$\mathrm{CD} 4^{+} \mathrm{CD} 28^{\text {null }} \mathrm{T}$ cells to produce inflammatory cytokines (IFN- $\gamma$ and TNF- $\alpha$ ) and to release cytotoxic enzymes. Serum levels of soluble OX40L (sOX40L) were increased in patients with ACS and correlated with higher risk for severe coronary events (i.e., myocardial infarction, recurrent angina, and sudden death) $[67,90]$. sOX40L levels were also shown to correlate with carotid intima-media thickness and C-reactive protein (CRP), while there was an indirect correlation with IL-10, a potent immune-suppressive cytokine [90, 92]. Notably, the levels of sOX40L decreased significantly in patients with stroke that received statins compared to those on routine medication [93]. In conclusion, these findings suggest that OX40/OX40L costimulation enhances inflammation and promotes the development of atherosclerosis and destabilisation of atherosclerotic plaques.

\section{4-1BB and 4-1BBL}

$4-1 \mathrm{BB}$ (CD137) is a potent and independent costimulatory receptor of T cells. Similarly to OX40, 4-1BB is not expressed by resting $\mathrm{T}$ cells, but induced on $\mathrm{T}$ cells hours to days following antigen recognition [94] (Table 1). Its costimulatory activity is triggered upon binding to its ligand 4$1 \mathrm{BBL}$, present on APCs, and is responsible for promoting the activation, survival, and function of effector T cells [94]. In addition to $\mathrm{T}$ cells, $4-1 \mathrm{BB}$ is widely expressed among the cells of the immune system in particular monocytes, DCs, NK and NKT cells, neutrophils, and eosinophils [94]. Similarly, 4-1BBL is not restricted to APCs but was also found in human primary $\mathrm{T}$ cells [95]. Of note, at sites of inflammation, 4-1BBL can be expressed by nonimmune cells such as cardiac myocytes in myocarditis and aortic tissue in arteritis [96, 97]. Although 4-1BB costimulatory signals augment T-cell activation and survival, it was unexpectedly found that 4-1BB-deficient $\mathrm{T}$ cells [98] and 4-1BB-deficient myeloid progenitors are hyperproliferative [76]. In addition to providing costimulatory signals for T-cell activation, 4$1 \mathrm{BB}$ ligation by $4-1 \mathrm{BBL}$ can also trigger signalling pathways in the cells that express the ligand 4-1BBL, which is also called reverse signalling [99]. Monocytes, macrophages, and DCs express 4-1BBL and reverse signalling has been shown to promote their activation, migration, and survival [100].

Several investigations have shown that $4-1 \mathrm{BB} / 4-1 \mathrm{BBL}$ interactions contribute to the pathogenesis of various diseases associated with chronic inflammation, including rheumatoid arthritis, allograft rejection, and cancer [101-103]. Recently, increasing evidence suggests that $4-1 \mathrm{BB} / 4-1 \mathrm{BBL}$ signals have proatherogenic roles (Table 2). A study from Olofsson and colleagues clearly demonstrated that $4-1 \mathrm{BB}$ is expressed in atherosclerotic plaques on $\mathrm{T}$ cells and endothelium [104]. Moreover, the authors showed that $A_{p o e^{-/-}}$ mice treated with an agonist monoclonal antibody against 4-1BB developed increased atherosclerosis and that high levels of infiltrating $\mathrm{T}$ cells and inflammatory cytokines were detected in atherosclerotic plaques. The authors proposed that interaction of 4-1BB costimulatory receptor (expressed on $\mathrm{T}$ lymphocytes and endothelial cells) with 4-1BBL (on macrophages) may enhance activation of $\mathrm{T}$ cells and endothelial cells and ultimately contribute to plaque inflamma- tion and disease aggravation. Of note, it was found that in the hypoxic environment of tumours the expression of 4$1 \mathrm{BB}$ is upregulated on endothelial cells [105]. Furthermore, administration of agonist 4-1BB antibodies increased the expression of adhesion molecules (i.e., ICAM-1, VCAM-1 and selectin) by endothelium and promoted entry of activated $T$ cells into the tumour [105]. Hypoxia was also described in human atherosclerotic lesions in areas rich in macrophages and is believed to promote development of advanced plaques by increasing inflammation and angiogenesis [106]. Therefore, it is possible that hypoxia is one of the factors that is responsible for the expression of $4-1 \mathrm{BB}$ on the endothelium in atherosclerotic plaques.

Further proof of the role of $4-1 \mathrm{BB} / 4-1 \mathrm{BBL}$ signalling in atherosclerosis comes from $A p o e^{-/-} c d 137^{-/-}$and $\mathrm{Ldll}^{-/-} c d 137^{-/-}$mice that showed reduced atherosclerosis [107]. 4-1BB (CD137) deficiency in these double knock-out mice decreased the production of inflammatory cytokines such as IFN- $\gamma$, tumour necrosis factor- $\alpha$ (TNF- $\alpha$ ), and monocyte chemoattractant protein-1 (MCP-1). Inhibition of these inflammatory mediators may decrease leucocyte recruitment and could therefore prevent plaque progression and rupture [107]. Blockade of 4-1BB/4-1BBL pathway was also shown to suppress neointimal hyperplasia in an experimental model of vascular injury [108].

Patients with ACS were found to have increased levels of 4-1BB on circulating monocytes and elevated serum soluble 4-1BB (s4-1BB) compared to SA patients and healthy individuals $[109,110]$. Moreover, 4-1BB levels correlated with the presence of complex coronary stenosis [110]. In a recent study, we showed that in ACS, $4-1 \mathrm{BB}$ was present in higher levels on $\mathrm{CD} 4{ }^{+} \mathrm{CD} 28^{\text {null }} \mathrm{T}$ cells than on conventional $\mathrm{CD} 4^{+} \mathrm{CD} 28^{+} \mathrm{T}$ lymphocytes [91]. Similarly to OX40, 4$1 \mathrm{BB}$ blockade decreased IFN- $\gamma$ and TNF- $\alpha$ secretion from $\mathrm{CD} 4{ }^{+} \mathrm{CD} 28^{\text {null }} \mathrm{T}$ cells and downregulated their cytotoxic potential. An increase in $\mathrm{s} 4-1 \mathrm{BB}$ was also found in patients with multiple sclerosis, rheumatoid arthritis, and haematological malignancies [111-113], and it has been suggested that it could reflect strong lymphocyte activation in vivo [112]. This could be the case even in atherosclerosis, which is often accompanied by activation and proliferation of $\mathrm{T}$ cells in atherosclerotic plaques [11]. These findings suggest that blockade of $4-1 \mathrm{BB} / 4-1 \mathrm{BBL}$ axis could be used to modulate progression of atherosclerotic lesions.

Experimental therapeutic approaches that block 4$1 \mathrm{BB} / 4-1 \mathrm{BBL}$ axis proved successful in the treatment of several inflammatory diseases. Administration of a 4-1BBimmunoglobulin fusion protein (4-1BB-Ig) attenuated experimental autoimmune myocarditis by decreasing the production of inflammatory cytokines (IL-1, IL-6 and TNF- $\alpha$ ) [114]. 4-1BB-Ig was also shown to decrease the development of graft arterial disease (GAD) in cardiac allografts [115]. In this model, blockade of 4-1BB inhibited infiltration with $\mathrm{T}$ cells and the expression of inflammatory cytokines in the grafted tissue. The authors proposed that modulation of the $4-1 \mathrm{BB}$ pathway may be a novel strategy to attenuate GAD following heart transplantation [115]. In line with these results, administration of agonistic antibodies for 4-1BB accelerated rejection of corneal allografts [116]. Similarly, 
treatment with neutralising antibodies against 4-1BBL during viral myocarditis decreased inflammation, T-cell infiltration, and overall improved long-term cardiac function [117]. In view of these positive results in experimental models, the effectiveness of $4-1 \mathrm{BB}-\mathrm{Ig}$ fusion protein and anti-4-1BBL neutralizing antibodies needs to be investigated in human atherosclerosis.

\section{CD27 and CD70}

Another member of the costimulatory TNFR family that is known to play a role in T-cell activation is CD27. In contrast to OX40 and $4-1 \mathrm{BB}$, naive $\mathrm{T}$ cells (both $\mathrm{CD}^{+}$and $\mathrm{CD}^{+}$ T lymphocytes) constitutively express CD27 (Table 1) [118]. In addition, this receptor is also present on thymocytes, B cells (especially memory B cells for which CD27 is a marker), and NK cells $[118,119]$. Its expression in activated $\mathrm{T}$ cells increases following TCR/CD3 signalling and is then downregulated with differentiation into effector T cells. The ligand for CD27 (CD70 or CD27L) is present on APCs and B cells, and similar to OX40L and 4-1BBL was also found on activated T cells $[120,121]$. CD27 regulates the generation of effector $\mathrm{T}$ cells by promoting the proliferation and survival of $\mathrm{T}$ cells following activation both in primary and memory immune responses. In addition, CD27 enhances the differentiation of B cells into plasma cells and the production of antibodies [119]. Moreover, interaction of CD27 on B cells with CD70 on activated $\mathrm{CD}^{+} \mathrm{T}$ cells promotes the expansion and survival of these T cells. However, sustained CD27CD70 interactions may cause immune pathology as it is often the case in diseases associated with persistent immune activation such as autoimmunity and chronic infections.

The role of CD27-CD70 signalling in atherosclerosis is still under investigation (Table 2). CD27 and CD70 were identified in $\mathrm{T}$ cells and macrophages in human atherosclerotic plaques [122]. In addition, increased levels of soluble CD27 have been documented in other diseases driven by persistent immune activation (autoimmunity and chronic viral infection) [123]. Whether the same is true for patients with atherosclerosis is currently unknown. When compared to healthy individuals, patients with myocardial infarction were found to have decreased levels of a Treg cell subset characterized by high suppressive potential, which are identified by the expression of CD27 (CD27 ${ }^{+}$Treg cells) [124]. The authors suggested that CD27 expression is irreversibly downregulated on Treg cells due to chronic activation of this cell subset in the inflammatory context of atherosclerosis. A recent study showed that CD70 transgenic Apoe ${ }^{-/-}$mice were protected from atherosclerosis, possibly due to a predisposition of circulating monocytes to apoptosis [125].

No data is currently available on targeting of CD27/CD70 in atherosclerosis. However, modulation of this costimulatory pathway was tested with success in autoimmunity and transplantation. In an experimental autoimmune encephalomyelitis model, anti-CD70 antibodies prevented disease progression [126]. Surprisingly, this effect was not mediated by inhibition of T-cell activation but was attributed to a decrease in the production of TNF- $\alpha$. Similarly, blockade of the CD27/CD70 pathway prolonged the survival of heart allografts [127]. In this study, treatment with anti-CD70 antibodies reduced the generation of memory $\mathrm{T}$ cells and resulted in decreased infiltration of allografts by effector $\mathrm{CD}^{+} \mathrm{T}$ cells. The authors also found that the percentage of Treg cells was increased by anti-CD70 treatment, suggesting that intragraft Treg cells could contribute to prolonged allograft survival. One could envisage that a similar mechanism of immunosuppression could be in place in atherosclerotic plaques. Whether targeting the CD27/CD70 costimulatory pathway could slow down atherosclerosis progression needs to be tested in the future.

\section{Novel TNFR Costimulatory Members and Atherosclerosis}

Other members of the TNFR family that have costimulatory effects on T cells are CD30, HVEM (herpes virus entry mediator), and GITR (glucocorticoid-induced TNFR family related gene). These relatively new TNFR family members were found to have direct roles in regulation of T-cell responses following initial T-cell activation [25, 35]. CD30 is found on activated T cells, B lymphocytes, eosinophils, and NK cells (Table 1) [128]. Its ligand, CD30L, is present on B cells and induced on T cells following activation [129, 130]. In primary $\mathrm{T}$ cells, CD30 ligation enhances proliferation and cytokine production, similar to other costimulatory receptors [131, 132]. However, in lymphoma cell lines it was found that CD30/CD30L signalling can trigger apoptosis [133]. HVEM is expressed by resting T cells and APCs such as DCs and monocytes $[134,135]$. The main ligand of HVEM is LIGHT, which is found on monocytes, DCs, NK cells, and also activated $\mathrm{CD}^{+}$and $\mathrm{CD}^{+} \mathrm{T}$ lymphocytes $[134,135]$. In addition, HVEM was also found to interact with lymphotoxin- $\alpha$, BTLA (B and T lymphocyte attenuator), and CD160. LIGHT and lymphotoxin- $\alpha$ promote $\mathrm{T}$-cell activation, while BTLA and CD160 have coinhibitory effects [136]. It has been suggested that HVEM is downregulated following activation of $\mathrm{T}$ cells, although in vivo studies have found persistent expression of both HVEM and LIGHT [137]. HVEM/ LIGHT interaction promotes T-cell activation and cytokine production [138]. Resting $\mathrm{T}$ cells express low levels of GITR, which is upregulated in activated $\mathrm{CD} 4^{+}$and $\mathrm{CD} 8^{+}$ T lymphocytes $[139,140]$. Of note, Treg cells constitutively express high levels of GITR, which has been suggested to contribute to their suppressive function $[141,142]$. The expression of GITRL is mainly confined to APCs (e.g., macrophages, DCs, and B lymphocytes). GITR ligation enhances the proliferation and viability of activated $\mathrm{T}$ cells. In addition, GITR/GITRL upregulates the production of IL-2, IL-4, IFN$\gamma$, and IL-10 from T cells activated via TCR $[139,143]$. CD30, HVEM and GITR have been implicated in various autoimmune disorders (e.g., inflammatory bowel disease, rheumatoid arthritis) [144], cancer [145, 146], and diabetes [147].

Limited information is available on the involvement of these new TNFR family members in atherosclerosis (Table 2). Elevated levels of HVEM and LIGHT were found in the aortas of Apoe $e^{-/-}$mice compared to wild type animals [148]. The cells expressing these molecules were macrophages and 
endothelial cells present in the atherosclerotic lesions. In the human disease, HVEM and LIGHT have been detected in atherosclerotic plaques, mainly in macrophages and foam cells [149]. In the same study, in vitro HVEM ligation on a myelomonocytic cell line was found to elicit the production of matrix metalloproteinases (MMP-1, MMP-9, and MMP13). Furthermore, immunohistochemistry of carotid atherosclerotic plaques showed that HVEM and MMP staining overlap [149]. The authors suggested that HVEM signalling could promote plaque rupture via induction of MMPs. Patients with unstable angina had significantly higher plasma levels of LIGHT compared to controls [150]. Similarly, elevated LIGHT plasma levels were found in patients with ischemic (atherosclerotic) stroke [151]. GITR/GITRL interactions have also been reported in atherosclerosis. Indeed, GITR and its ligand were identified in human atherosclerotic plaques mainly in lipid-rich macrophages [152]. Moreover, GITR-positive cells were observed in the intima in all stages of atherosclerotic plaque development, while highrisk plaques displayed focal accumulation of GITR-expressing cells. Of note, GITR staining overlapped with the staining for the proinflammatory cytokine TNF- $\alpha$ and the matrix metalloproteinase MMP-9 [152]. As GITR ligation triggered the production of inflammatory cytokines and MMP-9 from human and murine monocyte/macrophage cells lines, the authors suggested that GITR has proatherogenic roles by promoting macrophage activation and secretion of inflammatory cytokines and MMPs. A study that analysed the frequency of Treg cells in atherosclerotic lesions found that although GITR-positive Treg cells were present in the intima, their number was reduced compared to those found in healthy and inflamed skin [153]. Future research is required to establish the precise roles of CD30, HVEM, and GITR in atherosclerosis.

\section{The Role of TRAFs in Atherosclerosis}

TRAF proteins have been found to have key roles in the regulation of normal and pathogenic immune responses [154]. Recent studies also implicate TRAF proteins in atherosclerosis. All six types of mammalian TRAF members (TRAF1-6) were expressed in both human and murine atherosclerotic plaques. They were present mainly in endothelial cells and macrophages in atherosclerotic lesions and are therefore believed to regulate the activation of proinflammatory pathways in these cells [155]. TRAF1 deficiency was shown to attenuate atherogenesis in $\mathrm{Ldlr}^{-/-}$mice [156]. The authors of this study suggested that impaired monocyte recruitment into the vessel wall was the most likely underlying mechanism as the atherosclerotic plaques from TRAF1-deficient animals has significantly fewer macrophages [156]. However, other TRAF members were found to have opposite effects on the development and progression of atherosclerosis. Indeed, TRAF5 deficiency was shown to accelerate atherogenesis in $\mathrm{Ldlr}^{-/-}$mice possibly due to increased recruitment of monocytes/macrophages into the vessel wall and enhanced differentiation into foam cells [157]. TRAF6 interactions in leukocytes were also shown to play a key role in atherosclerosis. Neointima formation and arterial remodelling was reduced in mice with defects in CD40-TRAF6 [48]. Furthermore, specific disruption of CD40-TRAF6 in $A p o e^{-/-}$mice markedly reduced atherosclerosis and reduced the recruitment of inflammatory macrophages into the arterial wall [158]. Contrasting results were found when the role of TRAF6 from haematopoietic cells was investigated in atherosclerosis. TRAF6 deficiency did not alter the formation of atherosclerotic plaques in $\mathrm{Ldlr}^{-/-}$mice [159]. It is possible that these divergent results suggest that the roles of TRAFs in atherosclerosis may vary with the type of the stimulus, receptors, or cell type involved in the propagation of the costimulatory signal. Further investigations are required to clarify the effects of TRAFs in atherosclerosis.

\section{Modulation of Costimulatory Receptors of the TNFR Family and Future Clinical Applications in Atherosclerosis}

Current therapies aimed at downregulating the immune response in disorders associated with chronic inflammation (autoimmunity, inflammatory diseases, organ transplantation) associate with an increased risk of infection due to systemic immunosuppression. These effects are caused by nonspecific inhibition of all $\mathrm{T}$ cells and not only of those $\mathrm{T}$ lymphocytes that are actively involved in the disease process. A more efficient approach would be to specifically target the pathogenic $\mathrm{T}$ cells, while leaving untouched the rest of these cells. In addition, if the same therapeutic agent would also expand Treg cells and/or boost their suppressive function, it could further help to limit the inflammatory process and control the disease. As described in the previous sections, costimulatory receptors of the TNFR family are involved in many disorders associated with chronic inflammation. Therefore they represent promising targets for immunotherapy, either to switch off the pathogenic immune response in autoimmune or chronic inflammatory diseases by blockade of costimulatory pathways, or to enhance adaptive immune responses to combat tumours or chronic infections by active induction of costimulatory signals. (Note: the applications of TNFR costimulatory receptor modulation in cancer are beyond the scope of this review and will not be discussed.)

One of the features of the TNFR costimulatory receptors that makes them particularly suited for immunotherapy is their preferential expression by pathogenic effector $\mathrm{T}$ cells. This is in particular true for OX40 and 4-1BB, which are absent from naive/resting $\mathrm{T}$ cells and induced only following activation of naive or memory $\mathrm{T}$ lymphocytes [70, 140]. Therefore, targeting these receptors could allow specific elimination/inactivation of pathogenic $\mathrm{T}$ lymphocytes. In addition, as OX40 regulates effector T-cell migration and infiltration into inflamed tissues by interaction with OX40L on endothelial cells $[81,160]$, blockade of OX40 could also reduce tissue recruitment of pathogenic $\mathrm{T}$ cells. Another feature that could prove useful in therapeutic applications is the ability of several TNFR costimulatory receptors to promote survival of T lymphocytes [74]. Blockade of TNFR could therefore enhance apoptosis of pathogenic T cells. As 
previously mentioned, the efficacy of immunemodulation in chronic inflammation could be dramatically increased if downregulation of effector $\mathrm{T}$ cells could be accompanied by expansion of Treg cells and/or enhanced suppressive function. Both OX40 and 4-1BB were found to control the differentiation and function of Treg cells, although the information available is still conflicting. OX40 and 4-1BB were found to suppress Foxp3 and IL-10 expression in CD4 ${ }^{+}$ Treg cells, while enhancing the proliferation and survival of both $\mathrm{CD}^{+}$and $\mathrm{CD}^{+}$Treg cells [77-80, 161]. The effects of OX40 and 4-1BB pathways on the function of Treg cells are not fully understood, with reports of both inhibition and potentiation of suppressive abilities [78, 80, 162, 163]. However, it is clear that targeting OX40 and 4-1BB could modulate the expansion and/or suppressive function of Treg cells. Of note, human Treg cells do not express OX40 [164], which should protect them from inhibition/deletion by OX40 blockade.

An array of pharmacological tools has been developed to modulate the interactions between TNFR costimulatory receptors and their ligands that have yielded encouraging results in preclinical studies and are now tested in patients with asthma, autoimmunity, or cancer [25]. Blockade of TNFR costimulatory signals can be achieved by administration of neutralising monoclonal antibodies specific for costimulatory receptors/ligands (e.g., neutralising antibodies against OX40L, 4-1BBL, CD70) or TNFR-Ig fusion proteins that work by binding to ligands and preventing their subsequent interaction with costimulatory receptors (e.g., OX40-Ig, 4-1BB-Ig) [165-168]. These antibodies could be further engineered to express a cellular toxin or to trigger antibody-dependent cell-mediated cytotoxicity to enable specific elimination of target cells. Agonistic antibodies that stimulate TNFR signalling have also been generated to boost anti-tumour immune responses (e.g., agonistic antibodies to OX40, 4-1BB, and CD27). Surprisingly, it was found that 41BB-specific agonistic antibodies have beneficial immunosuppressive effects in various models of autoimmunity (e.g., lupus, arthritis, diabetes, encephalomyelitis, colitis) and inflammation (transplantation and asthma), possibly due to expansion of $\mathrm{CD}^{+}$Treg cells and/or generation of $\mathrm{CD}^{+}$ suppressive $\mathrm{T}$ cells $[103,169]$. However, administration of agonist antibodies specific for $4-1 \mathrm{BB}$ to $A p o e^{-/-}$mice enhanced atherosclerosis [104], suggesting that these antibodies could have different effects in various inflammatory conditions. Whether cardiovascular events could be precipitated by the administration of agonistic antibodies to 4-1BB (and possibly OX40 and CD27) is not yet known. However, as these antibodies would be preferentially administered to patients with advanced carcinoma to enhance the antitumoral immune response, the benefit of tumour control may outweigh the risk of cardiovascular events. Modulation of TRAF signalling could also provide a novel therapeutic option for the treatment of atherosclerosis.

Several difficulties still hinder the design of clinical therapeutic protocols based on modulation of TNFR costimulatory pathways. Some of these costimulatory receptors have a more broad expression than OX40 and 4-1BB that could lead to unwanted effects. The best example is CD40 that is constitutively expressed on platelets and triggers platelet activation and thrombosis following ligation by CD40L (i.e., induced on activated platelets) $[51,68]$. As expected, CD40 blockade was complicated by thrombotic events in humans $[49,69]$. Therapeutic strategies that enable cell-subset-specific targeting of costimulatory receptors/ligands are needed for clinical applications. Another issue that complicates the clinical translation of costimulatory receptor modulation is that most of the data on the roles of TNF receptors and ligands originate from studies done on animals and much more limited information is available about the expression and roles of these molecules in various stages of human disease. This limitation is further potentiated by the gap in the knowledge of immune mechanisms that underlie human disease versus animal models of the disease. This is particularly true in the case of atherosclerosis, where stark differences exist between the pathogenic mechanisms of atherosclerosis in animal models and the human disease. In addition, appropriate models to dissect the mechanisms responsible for atherosclerotic plaque rupture are still awaited. Another complication arises from the complexity of the costimulatory TNFR pathways, with several members regulating independently or in concert the activation, proliferation, survival, and function of effector $\mathrm{T}$ cells. Future studies based on animal models that better reproduce the evolution of human disease will hopefully clarify some of these issues and will close the gap between experimental data and clinical application of TNFR modulation.

\section{Conclusion}

Costimulatory receptors and ligands of the TNFR/TNF superfamily provide vital signals that promote the activation and survival of $\mathrm{T}$ cells and guide the differentiation and function of effector/memory $\mathrm{T}$ cells. It is therefore not surprising that recent research has shown that these receptors and ligands have important roles in regulating the immune response that underlies atherosclerosis. Importantly, data available so far paint an optimistic picture for future clinical applications of TNFR modulation. In particular, OX40/OX40L and 4-1BB/4-1BBL are promising candidates for immunemodulation in atherosclerosis, with CD40/CD40L being marred by thromboembolic complications. The main advantages of immunemodulation of OX40/OX40L or $4-1 \mathrm{BB} / 4-1 \mathrm{BBL}$ are specific targeting of pathogenic effector $\mathrm{T}$ cells without generalised immunosuppression of T cells; inhibition of both proliferation and survival of activated T cells; concomitant induction of Treg cells and/or amplification of their suppressive function. However, future research is still required to clarify some points such as patient selection (responses may be better in patients that have enhanced levels of TNFR costimulatory receptors); which costimulatory receptor or combination of receptors is better to modulate the disease; timing and dosing of pharmacological reagents; which therapeutic reagent (neutralising antibodies, depleting antibodies, TNFR-Ig-fusion proteins, TRAF inhibitors) induces the best clinical effects with minimum unwanted reactions. Hopefully, we are not very far from the day when TNFR 
targeting will lead to (co-)stimulating results in the clinical setting.

\section{Conflict of Interests}

The authors declare no conflict of interests.

\section{Acknowledgments}

The authors apologise for the seminal contributions that could not be cited in this work due to lack of space. The authors' research is supported by the the British Heart Foundation (Grant no. PG/10/50/28434, to IED and JCK) and St. George's Hospital Charity, London, UK.

\section{References}

[1] G. K. Hansson and A. Hermansson, "The immune system in atherosclerosis," Nature Immunology, vol. 12, no. 3, pp. 204212, 2011.

[2] G. K. Hansson and P. Libby, "The immune response in atherosclerosis: a double-edged sword," Nature Reviews Immunology, vol. 6, no. 7, pp. 508-519, 2006.

[3] G. K. Hansson, J. Holm, and L. Jonasson, "Detection of activated $\mathrm{T}$ lymphocytes in the human atherosclerotic plaque," American Journal of Pathology, vol. 135, no. 1, pp. 169-175, 1989.

[4] L. Jonasson, J. Holm, O. Skalli, G. Bondjers, and G. K. Hansson, "Regional accumulations of T cells, macrophages, and smooth muscle cells in the human atherosclerotic plaque," Arteriosclerosis, vol. 6, no. 2, pp. 131-138, 1986.

[5] P. X. Shaw, S. Hörkkö, M. K. Chang et al., "Natural antibodies with the T15 idiotype may act in atherosclerosis, apoptotic clearance, and protective immunity," Journal of Clinical Investigation, vol. 105, no. 12, pp. 1731-1740, 2000.

[6] J. Andersson, P. Libby, and G. K. Hansson, "Adaptive immunity and atherosclerosis," Clinical Immunology, vol. 134, no. 1, pp. 33-46, 2010.

[7] O. Acuto and F. Michel, "CD28-mediated co-stimulation: a quantitative support for TCR signalling," Nature Reviews Immunology, vol. 3, no. 12, pp. 939-951, 2003.

[8] C. Weber, A. Zernecke, and P. Libby, "The multifaceted contributions of leukocyte subsets to atherosclerosis: lessons from mouse models," Nature Reviews Immunology, vol. 8, no. 10, pp. 802-815, 2008.

[9] I. E. Dumitriu and J. C. Kaski, "The role of T and B cells in atherosclerosis: potential clinical implications," Current Pharmaceutical Design. In press.

[10] M. Hosono, O. J. De Boer, A. C. Van Der Wal et al., "Increased expression of T cell activation markers (CD25, CD26, CD40L and CD69) in atherectomy specimens of patients with unstable angina and acute myocardial infarction," Atherosclerosis, vol. 168, no. 1, pp. 73-80, 2003.

[11] M. D. Rekhter and D. Gordon, "Active proliferative of different cell types, including lymphocytes, in human atherosclerotic plaques," American Journal of Pathology, vol. 147, no. 3, pp. 668-677, 1995.

[12] J. Khallou-Laschet, G. Caligiuri, E. Groyer et al., "The proatherogenic role of $\mathrm{T}$ cells requires cell division and is dependent on the stage of the disease," Arteriosclerosis, Thrombosis, and Vascular Biology, vol. 26, no. 2, pp. 353-358, 2006.
[13] A. K. L. Robertson and G. K. Hansson, "T cells in atherogenesis: for better or for worse?" Arteriosclerosis, Thrombosis, and Vascular Biology, vol. 26, no. 11, pp. 2421-2432, 2006.

[14] A. Daugherty and D. L. Rateri, "T lymphocytes in atherosclerosis the Yin-Yang of Th1 and Th2 influence on lesion formation," Circulation Research, vol. 90, no. 10, pp. 10391040, 2002.

[15] X. Zhou, A. Nicoletti, R. Elhage, and G. K. Hansson, "Transfer of $\mathrm{CD}^{+} \mathrm{T}$ cells aggravates atherosclerosis in immunodeficient apolipoprotein E knockout mice," Circulation, vol. 102, no. 24, pp. 2919-2922, 2000.

[16] N. Pejnovic, A. Vratimos, S. H. Lee et al., "Increased atherosclerotic lesions and Th17 in interleukin-18 deficient apolipoprotein E-knockout mice fed high-fat diet," Molecular Immunology, vol. 47, no. 1, pp. 37-45, 2009.

[17] E. Smith, K. M. R. Prasad, M. Butcher et al., "Blockade of interleukin-17A results in reduced atherosclerosis in apolipoprotein E-deficient mice," Circulation, vol. 121, no. 15, pp. 1746-1755, 2010.

[18] T. van Es, G. H. M. van Puijvelde, O. H. Ramos et al., "Attenuated atherosclerosis upon IL-17R signaling disruption in LDLr deficient mice," Biochemical and Biophysical Research Communications, vol. 388, no. 2, pp. 261-265, 2009.

[19] S. E. Epstein, J. Zhu, M. S. Burnett, Y. F. Zhou, G. Vercellotti, and D. Hajjar, "Infection and atherosclerosis: potential roles of pathogen burden and molecular mimicry," Arteriosclerosis, Thrombosis, and Vascular Biology, vol. 20, no. 6, pp. 14171420, 2000.

[20] W. Palinski, R. K. Tangirala, E. Miller, S. G. Young, and J. L. Witztum, "Increased autoantibody titers against epitopes of oxidized LDL in LDL receptor-deficient mice with increased atherosclerosis," Arteriosclerosis, Thrombosis, and Vascular Biology, vol. 15, no. 10, pp. 1569-1576, 1995.

[21] Q. Xu, R. Kleindienst, W. Waitz, H. Dietrich, and G. Wick, "Increased expression of heat shock protein 65 coincides with a population of infiltrating $\mathrm{T}$ lymphocytes in atherosclerotic lesions of rabbits specifically responding to heat shock protein 65," Journal of Clinical Investigation, vol. 91, no. 6, pp. 2693-2702, 1993.

[22] C. Monaco, F. Crea, G. Niccoli et al., "Autoantibodies against oxidized low density lipoproteins in patients with stable angina, unstable angina or peripheral vascular disease: pathophysiological implications," European Heart Journal, vol. 22, no. 17, pp. 1572-1577, 2001.

[23] Q. Xu, G. Schett, H. Perschinka et al., "Serum soluble heat shock protein 60 is elevated in subjects with atherosclerosis in a general population," Circulation, vol. 102, no. 1, pp. 1420, 2000.

[24] P. Aukrust, A. Yndestad, W. J. Sandberg, L. Gullestad, and J. K. Damås, "T cells in coronary artery disease: different effects of different T-cell subsets," Journal of the American College of Cardiology, vol. 50, no. 15, pp. 1459-1461, 2007.

[25] M. Croft, "The role of TNF superfamily members in T-cell function and diseases," Nature Reviews Immunology, vol. 9, no. 4, pp. 271-285, 2009.

[26] R. A. Seder, R. Gazzinelli, A. Sher, and W. E. Paul, "Interleukin 12 acts directly on $\mathrm{CD}^{+} \mathrm{T}$ cells to enhance priming for interferon $\gamma$ production and diminishes interleukin 4 inhibition of such priming," Proceedings of the National Academy of Sciences of the United States of America, vol. 90, no. 21, pp. 10188-10192, 1993.

[27] G. Le Gros, S. Z. Ben-Sasson, R. Seder, F. D. Finkelman, and W. E. Paul, "Generation of interleukin 4 (IL-4)-producing 
cells in vivo and in vitro: IL-2 and IL-4 are required for in vitro generation of IL-4-producing cells," Journal of Experimental Medicine, vol. 172, no. 3, pp. 921-929, 1990.

[28] E. Bettelli, Y. Carrier, W. Gao et al., "Reciprocal developmental pathways for the generation of pathogenic effector $\mathrm{T}_{H} 17$ and regulatory T cells," Nature, vol. 441, no. 7090, pp. 235 238, 2006.

[29] J. Das, G. Ren, L. Zhang et al., "Transforming growth factor $\beta$ is dispensable for the molecular orchestration of Th17 cell differentiation," Journal of Experimental Medicine, vol. 206, no. 11, pp. 2407-2416, 2009.

[30] P. R. Mangan, L. E. Harrington, D. B. O’Quinn et al., “Transforming growth factor- $\beta$ induces development of the $\mathrm{T}_{H} 17$ lineage," Nature, vol. 441, no. 7090, pp. 231-234, 2006.

[31] H. Ait-Oufella, S. Taleb, Z. Mallat, and A. Tedgui, "Recent advances on the role of cytokines in atherosclerosis," Arteriosclerosis, Thrombosis, and Vascular Biology, vol. 31, no. 5, pp. 969-979, 2011.

[32] A. H. Sharpe and G. J. Freeman, "The B7-CD28 superfamily," Nature Reviews Immunology, vol. 2, no. 2, pp. 116-126, 2002.

[33] C. Dong, A. E. Juedes, U. A. Temann et al., "ICOS costimulatory receptor is essential for T-cell activation and function," Nature, vol. 409, no. 6816, pp. 97-101, 2001.

[34] A. H. Sharpe, E. J. Wherry, R. Ahmed, and G. J. Freeman, "The function of programmed cell death 1 and its ligands in regulating autoimmunity and infection," Nature Immunology, vol. 8, no. 3, pp. 239-245, 2007.

[35] T. H. Watts, "TNF/TNFR family members in costimulation of T cell responses," Annual Review of Immunology, vol. 23, pp. 23-68, 2005.

[36] A. H. Sharpe, "Mechanisms of costimulation," Immunological Reviews, vol. 229, no. 1, pp. 5-11, 2009.

[37] M. Croft, "Costimulatory members of the TNFR family: keys to effective T-cell immunity?" Nature Reviews Immunology, vol. 3, no. 8, pp. 609-620, 2003.

[38] P. W. Dempsey, S. E. Doyle, J. Q. He, and G. Cheng, "The signaling adaptors and pathways activated by TNF superfamily," Cytokine and Growth Factor Reviews, vol. 14, no. 34, pp. 193-209, 2003.

[39] J. M. Zapata, "TNF-receptor-associated factors as targets for drug development," Expert Opinion on Therapeutic Targets, vol. 7, no. 3, pp. 411-425, 2003.

[40] H. Akiba, H. Nakano, S. Nishinaka et al., "CD27, a member of the tumor necrosis factor receptor superfamily, activates NF- $\kappa \mathrm{B}$ and stress-activated protein kinase/c-Jun N-terminal kinase via TRAF2, TRAF5, and NF- $\kappa$ B-inducing kinase," Journal of Biological Chemistry, vol. 273, no. 21, pp. 13353 13358, 1998.

[41] J. Song, S. Salek-Ardakani, T. So, and M. Croft, "The kinases aurora B and mTOR regulate the G1-S cell cycle progression of T lymphocytes," Nature Immunology, vol. 8, no. 1, pp. 6473, 2007.

[42] J. L. Cannons, Y. Choi, and T. H. Watts, "Role of TNF receptor-associated factor 2 and p38 mitogen-activated protein kinase activation during 4-1BB-dependent immune response," Journal of Immunology, vol. 165, no. 11, pp. 61936204, 2000.

[43] M. Cayabyab, J. H. Phillips, and L. L. Lanier, "CD40 preferentially costimulates activation of $\mathrm{CD}^{+} \mathrm{T}$ lymphocytes," Journal of Immunology, vol. 152, no. 4, pp. 1523-1531, 1994.

[44] I. S. Grewal and R. A. Flavell, "CD40 and CD154 in cellmediated immunity," Annual Review of Immunology, vol. 16, pp. 111-135, 1998.
[45] G. A. Bishop and B. S. Hostager, "The CD40-CD154 interaction in B cell-T cell liaisons," Cytokine and Growth Factor Reviews, vol. 14, no. 3-4, pp. 297-309, 2003.

[46] M. Melter, M. E. J. Reinders, M. Sho et al., "Ligation of CD40 induces the expression of vascular endothelial growth factor by endothelial cells and monocytes and promotes angiogenesis in vivo," Blood, vol. 96, no. 12, pp. 3801-3808, 2000.

[47] M. E. J. Reinders, M. Sho, S. W. Robertson, C. S. Geehan, and D. M. Briscoe, "Proangiogenic function of CD40 ligandCD40 interactions," Journal of Immunology, vol. 171, no. 3, pp. 1534-1541, 2003.

[48] M. M. P. C. Donners, L. Beckers, D. Lievens et al., "The cd40traf6 axis is the key regulator of the cd40/cd401 system in neointima formation and arterial remodeling," Blood, vol. 111, no. 9, pp. 4596-4604, 2008.

[49] D. Lievens, W. J. Eijgelaar, E. A. L. Biessen, M. J. A. P. Daemen, and E. Lutgens, "The multi-functionality of CD40L and its receptor CD40 in atherosclerosis," Thrombosis and Haemostasis, vol. 102, no. 2, pp. 206-214, 2009.

[50] F. Mach, U. Schönbeck, G. K. Sukhova et al., "Functional CD40 ligand is expressed on human vascular endothelial cells, smooth muscle cells, and macrophages: implications for CD40-CD40 ligand signaling in atherosclerosis," Proceedings of the National Academy of Sciences of the United States of America, vol. 94, no. 5, pp. 1931-1936, 1997.

[51] S. Danese and C. Fiocchi, "Platelet activation and the CD40/ CD40 ligand pathway: mechanisms and implications for human disease," Critical Reviews in Immunology, vol. 25, no. 2, pp. 103-121, 2005.

[52] F. Mach, U. Schönbeck, J. Y. Bonnefoy, J. S. Pober, and P. Libby, "Activation of monocyte/macrophage functions related to acute atheroma complication by ligation of CD40: induction of collagenase, stromelysin, and tissue factor," Circulation, vol. 96, no. 2, pp. 396-399, 1997.

[53] F. Mach, U. Schönbeck, G. K. Sukhova, E. Atkinson, and P. Libby, "Reduction of atherosclerosis in mice by inhibition of CD40 signalling," Nature, vol. 394, no. 6689, pp. 200-203, 1998.

[54] E. Lutgens, L. Gorelik, M. J. A. P. Daemen et al., "Requirement for CD154 in the progression of atherosclerosis," Nature Medicine, vol. 5, no. 11, pp. 1313-1316, 1999.

[55] U. Schönbeck, G. K. Sukhova, K. Shimizu, F. Mach, and P. Libby, "Inhibition of CD40 signaling limits evolution of established atherosclerosis in mice," Proceedings of the $\mathrm{Na}$ tional Academy of Sciences of the United States of America, vol. 97, no. 13, pp. 7458-7463, 2000.

[56] A. Zirlik, C. Maier, N. Gerdes et al., "CD40 ligand mediates inflammation independently of CD40 by interaction with Mac-1," Circulation, vol. 115, no. 12, pp. 1571-1580, 2007.

[57] U. Bavendiek, A. Zirlik, S. LaClair, L. MacFarlane, P. Libby, and U. Schönbeck, "Atherogenesis in mice does not require CD40 ligand from bone marrow-derived cells," Arteriosclerosis, Thrombosis, and Vascular Biology, vol. 25, no. 6, pp. 12441249, 2005.

[58] M. L. F. Smook, P. Heeringa, J. G. M. C. Damoiseaux et al., "Leukocyte CD40L deficiency affects the CD25+ CD4 T cell population but does not affect atherosclerosis," Atherosclerosis, vol. 183, no. 2, pp. 275-282, 2005.

[59] I. Gotsman, A. H. Sharpe, and A. H. Lichtman, "T-cell costimulation and coinhibition in atherosclerosis," Circulation Research, vol. 103, no. 11, pp. 1220-1231, 2008.

[60] X. F. Jiang, L. Zhu, Z. M. Cui et al., "Transplant longsurviving induced by CD40-CD40 ligand costimulation 
blockade is dependent on IFN- $\gamma$ through its effect on $\mathrm{CD} 4{ }^{+} \mathrm{CD} 25^{+}$regulatory T cells," Transplant Immunology, vol. 24, no. 2, pp. 113-118, 2011.

[61] P. Aukrust, F. Müller, T. Ueland et al., "Enhanced levels of soluble and membrane-bound CD40 ligand in patients with unstable angina: possible reflection of $\mathrm{T}$ lymphocyte and platelet involvement in the pathogenesis of acute coronary syndromes," Circulation, vol. 100, no. 6, pp. 614-620, 1999.

[62] T. Yoshioka, H. Funayama, H. Hoshino et al., "Association of CD40 ligand levels in the culprit coronary arteries with subsequent prognosis of acute myocardial infarction," Atherosclerosis, vol. 213, no. 1, pp. 268-272, 2010.

[63] C. Heeschen, S. Dimmeler, C. W. Hamm et al., "Soluble CD40 ligand in acute coronary syndromes," New England Journal of Medicine, vol. 348, no. 12, pp. 1104-1111, 2003.

[64] N. Varo, J. A. De Lemos, P. Libby et al., "Soluble CD40L: risk prediction after acute coronary syndromes," Circulation, vol. 108, no. 9, pp. 1049-1052, 2003.

[65] A. G. Semb, S. Van Wissen, T. Ueland et al., "Raised serum levels of soluble CD40 ligand in patients with familial hypercholesterolemia: downregulatory effect of statin therapy," Journal of the American College of Cardiology, vol. 41, no. 2, pp. 275-279, 2003.

[66] C. Wang, J. Yan, P. Yang, R. Du, and G. Chen, "The relationship between CD40 gene polymorphism and unstable coronary atherosclerotic plaques," Clinical Cardiology, vol. 33, no. 6, pp. E55-E60, 2010.

[67] J. Yan, J. Gong, G. Chen, P. Liu, C. Wang, and P. Yang, "Evaluation of serum soluble OX40 ligand as a prognostic indicator in acute coronary syndrome patients," Clinica Chimica Acta, vol. 411, no. 21-22, pp. 1662-1665, 2010.

[68] D. P. Inwald, A. McDowall, M. J. Peters, R. E. Callard, and N. J. Klein, "CD40 is constitutively expressed on platelets and provides a novel mechanism for platelet activation," Circulation Research, vol. 92, no. 9, pp. 1041-1048, 2003.

[69] T. Kawai, D. Andrews, R. B. Colvin et al., "Thromboembolic complications after treatment with monoclonal antibody against CD40 ligand," Nature Medicine, vol. 6, no. 2, p. 114, 2000.

[70] W. R. Godfrey, F. F. Fagnoni, M. A. Harara, D. Buck, and E. G. Engleman, "Identification of a human OX-40 ligand, a costimulator of $\mathrm{CD}^{+} \mathrm{T}$ cells with homology to tumor necrosis factor," Journal of Experimental Medicine, vol. 180, no. 2, pp. 757-762, 1994.

[71] W. L. Redmond, C. E. Ruby, and A. D. Weinberg, "The Role of OX40-mediated Co-stimulation in T-cell activation and survival," Critical Reviews in Immunology, vol. 29, no. 3, pp. 187-201, 2009.

[72] A. D. Weinberg, "OX40: targeted immunotherapy-implications for tempering autoimmunity and enhancing vaccines," Trends in Immunology, vol. 23, no. 2, pp. 102-109, 2002.

[73] I. Gramaglia, A. D. Weinberg, M. Lemon, and M. Croft, "Ox40 ligand: a potent costimulatory molecule for sustaining primary CD4 T cell responses," Journal of Immunology, vol. 161, no. 12, pp. 6510-6517, 1998.

[74] P. R. Rogers, J. Song, I. Gramaglia, N. Killeen, and M. Croft, "OX40 promotes $\mathrm{Bcl}-\mathrm{xL}$ and $\mathrm{Bcl}-2$ expression and is essential for long-term survival of CD4 T cells," Immunity, vol. 15, no. 3, pp. 445-455, 2001.

[75] W. Dawicki, E. M. Bertram, A. H. Sharpe, and T. H. Watts, "4-1BB and OX40 act independently to facilitate robust CD8 and CD4 recall responses," Journal of Immunology, vol. 173, no. 10, pp. 5944-5951, 2004.

[76] T. So, S. W. Lee, and M. Croft, "Immune regulation and control of regulatory T cells by OX40 and 4-1BB," Cytokine and Growth Factor Reviews, vol. 19, no. 3-4, pp. 253-262, 2008.

[77] M. Chen, X. Xiao, G. Demirci, and X. C. Li, “OX40 controls islet allograft tolerance in CD154 deficient mice by regulating FOXP $^{+}$tregs," Transplantation, vol. 85, no. 11, pp. 1659$1662,2008$.

[78] T. Ito, Y. H. Wang, O. Duramad et al., "0X40 ligand shuts down IL-10-producing regulatory T cells," Proceedings of the National Academy of Sciences of the United States of America, vol. 103, no. 35, pp. 13138-13143, 2006.

[79] T. So and M. Croft, "Cutting edge: OX40 inhibits TGF- $\beta$ and antigen-driven conversion of naive CD4 T cells into CD25 $5^{+}$Foxp $3^{+}$T cells," Journal of Immunology, vol. 179, no. 3, pp. 1427-1430, 2007.

[80] M. D. Vu, X. Xiao, W. Gao et al., "OX40 costimulation turns off Foxp3 $3^{+}$Tregs," Blood, vol. 110, no. 7, pp. 2501-2510, 2007.

[81] A. Imura, T. Hori, K. Imada et al., "The human OX40/GP34 system directly mediates adhesion of activated $\mathrm{T}$ cells to vascular endothelial cells," Journal of Experimental Medicine, vol. 183, no. 5, pp. 2185-2195, 1996.

[82] I. Mendel and E. M. Shevach, "Activated T cells express the OX40 ligand: requirements for induction and costimulatory function," Immunology, vol. 117, no. 2, pp. 196-204, 2006.

[83] X. Wang, M. Ria, P. M. Kelmenson et al., "Positional identification of TNFSF4, encoding OX40 ligand, as a gene that influences atherosclerosis susceptibility," Nature Genetics, vol. 37, no. 4, pp. 365-372, 2005.

[84] E. J. A. Van Wanrooij, G. H. M. Van Puijvelde, P. De Vos, H. Yagita, T. J. C. Van Berkel, and J. Kuiper, "Interruption of the Tnfrsf4/Tnfsf4 (OX40/OX40L) pathway attenuates atherogenesis in low-density lipoprotein receptor-deficient mice," Arteriosclerosis, Thrombosis, and Vascular Biology, vol. 27, no. 1, pp. 204-210, 2007.

[85] M. Nakano, Y. Fukumoto, K. Satoh et al., "OX40 ligand plays an important role in the development of atherosclerosis through vasa vasorum neovascularization," Cardiovascular Research, vol. 88, no. 3, pp. 539-546, 2010.

[86] A. Kotani, T. Hori, Y. Matsumura, and T. Uchiyama, "Signaling of gp34 (OX40 ligand) induces vascular endothelial cells to produce a CC chemokine RANTES/CCL5," Immunology Letters, vol. 84, no. 1, pp. 1-7, 2002.

[87] T. Hattori, Y. Usui, Y. Okunuki et al., "Blockade of the OX40 ligand prolongs corneal allograft survival," European Journal of Immunology, vol. 37, no. 12, pp. 3597-3604, 2007.

[88] M. Ria, P. Eriksson, S. Boquist, C. G. Ericsson, A. Hamsten, and J. Lagercrantz, "Human genetic evidence that OX40 is implicated in myocardial infarction," Biochemical and Biophysical Research Communications, vol. 339, no. 3, pp. 1001-1006, 2006.

[89] P. S. Olofsson, L. Å. Söderström, C. Jern et al., "Genetic variants of TNFSF4 and risk for carotid artery disease and stroke," Journal of Molecular Medicine, vol. 87, no. 4, pp. 337346, 2009.

[90] J. Yan, G. Chen, J. Gong, C. Wang, and R. Du, "Upregulation of OX40-OX40 ligand system on T lymphocytes in patients with acute coronary syndromes," Journal of Cardiovascular Pharmacology, vol. 54, no. 5, pp. 451-455, 2009.

[91] I. E. Dumitriu, P. Baruah, N. Bunce, and J. C. Kaski, "High levels of co-stimulatory receptors OX40 and 4-1BB characterise $\mathrm{CD} 4{ }^{+} \mathrm{CD} 28^{\text {null }} \mathrm{T}$ cells in patients with acute coronary syndrome".

[92] D. Q. Peng, S. Huang, S. G. Yuan, and S. P. Zhao, "Increased soluble OX40L is associated with carotid intima-media thickness," Clinical Laboratory, vol. 56, no. 9-10, pp. 449-457, 2010 . 
[93] B. Liu, G. Yu, Z. Yang et al., "Simvastatin reduces OX40 and OX40 ligand expression in human peripheral blood mononuclear cells and in patients with atherosclerotic cerebral infarction," Journal of International Medical Research, vol. 37, no. 3, pp. 601-610, 2009.

[94] C. Wang, G. H. Y. Lin, A. J. McPherson, and T. H. Watts, "Immune regulation by 4-1BB and 4-1BBL: complexities and challenges," Immunological Reviews, vol. 229, no. 1, pp. 192215, 2009.

[95] M. T. Stephan, V. Ponomarev, R. J. Brentjens et al., “T cellencoded CD80 and 4-1BBL induce auto- and transcostimulation, resulting in potent tumor rejection," Nature Medicine, vol. 13, no. 12, pp. 1440-1449, 2007.

[96] Y. Seko, K. Sugishita, O. Sato et al., "Expression of costimulatory molecules (4-1BBL and Fas) and major histocompatibility class I chain-related A (MICA) in aortic tissue with Takayasu's arteritis," Journal of Vascular Research, vol. 41, no. 1, pp. 84-90, 2004.

[97] Y. Seko, N. Takahashi, H. Oshima et al., "Expression of tumour necrosis factor (TNF) ligand superfamily costimulatory molecules CD30L, CD27L, OX40L, and 4-IBBL in murine hearts with acute myocarditis caused by coxsackievirus B3," Journal of Pathology, vol. 195, no. 5, pp. 593-603, 2001.

[98] B. S. Kwon, J. C. Hurtado, Z. H. Lee et al., "Immune responses in 4-1BB (CD137)-deficient mice," Journal of Immunology, vol. 168, no. 11, pp. 5483-5490, 2002.

[99] J. Langstein, J. Michel, J. Fritsche, M. Kreutz, R. Andreesen, and H. Schwarz, "CD137 (ILA/4-1BB), a member of the TNF receptor family, induces monocyte activation via bidirectional signaling," Journal of Immunology, vol. 160, no. 5, pp. 2488-2494, 1998.

[100] Z. Shao and H. Schwarz, "CD137 ligand, a member of the tumor necrosis factor family, regulates immune responses via reverse signal transduction," Journal of Leukocyte Biology, vol. 89, no. 1, pp. 21-29, 2011.

[101] H. R. Cho, B. Kwon, H. Yagita et al., "Blockade of 4-1BB (CD137)/4-1BB ligand interactions increases allograft survival," Transplant International, vol. 17, no. 7, pp. 351-361, 2004.

[102] R. S. Mittler, J. Foell, M. McCausland et al., "Anti-CD137 antibodies in the treatment of autoimmune disease and cancer," Immunologic Research, vol. 29, no. 1-3, pp. 197-208, 2004.

[103] S. K. Seo, J. H. Choi, Y. H. Kim et al., "4-1BB-mediated immunotherapy of rheumatoid arthritis," Nature Medicine, vol. 10, no. 10, pp. 1088-1094, 2004.

[104] P. S. Olofsson, L. Å. Söderström, D. Wågsäter et al., “CD137 is expressed in human atherosclerosis and promotes development of plaque inflammation in hypercholesterolemic mice," Circulation, vol. 117, no. 10, pp. 1292-1301, 2008.

[105] A. Palazón, A. Teijeira, I. Martínez-Forero et al., "Agonist anti-CD137 mAb act on tumor endothelial cells to enhance recruitment of activated T lymphocytes," Cancer Research, vol. 71, no. 3, pp. 801-811, 2011.

[106] L. M. Hultén and M. Levin, "The role of hypoxia in atherosclerosis," Current Opinion in Lipidology, vol. 20, no. 5, pp. 409-414, 2009.

[107] H. J. Jeon, J. H. Choi, I. H. Jung et al., "CD137 (4-1BB) deficiency reduces atherosclerosis in hyperlipidemic mice," Circulation, vol. 121, no. 9, pp. 1124-1133, 2010.

[108] A. Karube, J. I. Suzuki, G. Haraguchi et al., "Suppression of neointimal hyperplasia after vascular injury by blocking 4-1BB/4-1BB ligand pathway," Journal of Medical and Dental Sciences, vol. 55, no. 2, pp. 207-213, 2008.
[109] L. Dongming, L. Zuxun, X. Liangjie, W. Biao, and Y. Ping, "Enhanced levels of soluble and membrane-bound CD137 levels in patients with acute coronary syndromes," Clinica Chimica Acta, vol. 411, no. 5-6, pp. 406-410, 2010.

[110] J. Yan, J. Gong, P. Liu, C. Wang, and G. Chen, "Positive correlation between CD137 expression and complex stenosis morphology in patients with acute coronary syndromes," Clinica Chimica Acta, vol. 412, no. 11-12, pp. 993-998, 2011.

[111] W. Liu, A. L. Putnam, Z. Xu-yu et al., "CD127 expression inversely correlates with FoxP3 and suppressive function of human $\mathrm{CD}^{+}{ }^{+} \mathrm{T}$ reg cells," Journal of Experimental Medicine, vol. 203, no. 7, pp. 1701-1711, 2006.

[112] J. Michel and H. Schwarz, "Expression of soluble CD137 correlates with activation-induced cell death of lymphocytes," Cytokine, vol. 12, no. 6, pp. 742-746, 2000.

[113] H. R. Salih, H. M. Schmetzer, C. Burke et al., "Soluble CD137 (4-1BB) ligand is released following leukocyte activation and is found in sera of patients with hematological malignancies," Journal of Immunology, vol. 167, no. 7, pp. 4059-4066, 2001.

[114] T. Haga, J. I. Suzuki, H. Kosuge et al., "Attenuation of experimental autoimmune myocarditis by blocking $\mathrm{T}$ cell activation through 4-1BB pathway," Journal of Molecular and Cellular Cardiology, vol. 46, no. 5, pp. 719-727, 2009.

[115] H. Saiki, J. I. Suzuki, H. Kosuge et al., "Blockade of the 4-1BB pathway attenuates graft arterial disease in cardiac allografts," International Heart Journal, vol. 49, no. 1, pp. 105-118, 2008.

[116] T. Asai, B. K. Choi, P. M. Kwon et al., "Blockade of the 4-1BB (CD137)/4-1BBL and/or CD28/CD80/CD86 costimulatory pathways promotes corneal allograft survival in mice," Immunology, vol. 121, no. 3, pp. 349-358, 2007.

[117] C. T. Y. Cheung, T. A. Deisher, H. Luo et al., "Neutralizing anti-4-1BBL treatment improves cardiac function in viral myocarditis," Laboratory Investigation, vol. 87, no. 7, pp. 651661, 2007.

[118] M. A. Nolte, R. W. Van Olffen, K. P. J. M. Van Gisbergen, and R. A. W. Van Lier, "Timing and tuning of CD27-CD70 interactions: the impact of signal strength in setting the balance between adaptive responses and immunopathology," Immunological Reviews, vol. 229, no. 1, pp. 216-231, 2009.

[119] S. Jacquot, "CD27/CD70 interactions regulate T dependent B cell differentiation," Immunologic Research, vol. 21, no. 1, pp. 23-30, 2000.

[120] M. R. Bowman, M. A. V. Crimmins, J. Yetz-Aldape, R. Kriz, K. Kelleher, and S. Herrmann, "The cloning of CD70 and its identification as the ligand for CD27," Journal of Immunology, vol. 152, no. 4, pp. 1756-1761, 1994.

[121] R. Q. Hintzen, S. M. Lens, M. P. Beckmann, R. G. Goodwin, D. Lynch, and R. A. W. Van Lier, "Characterization of the human CD27 ligand, a novel member of the TNF gene family," Journal of Immunology, vol. 152, no. 4, pp. 17621773, 1994.

[122] O. J. De Boer, F. Hirsch, A. C. Van Der Wal, C. M. Van Der Loos, P. K. Das, and A. E. Becker, "Costimulatory molecules in human atherosclerotic plaques: an indication of antigen specific T lymphocyte activation," Atherosclerosis, vol. 133, no. 2, pp. 227-234, 1997.

[123] S. M. A. Lens, K. Tesselaar, M. H. J. Van Oers, and R. A. W. Van Lier, "Control of lymphocyte function through CD27CD70 interactions," Seminars in Immunology, vol. 10, no. 6, pp. 491-499, 1998.

[124] G. Sardella, L. De Luca, V. Francavilla et al., "Frequency of naturally-occurring regulatory $\mathrm{T}$ cells is reduced in patients with ST-segment elevation myocardial infarction," Thrombosis Research, vol. 120, no. 4, pp. 631-634, 2007. 
[125] R. W. Van Olffen, A. M. De Bruin, M. Vos et al., "CD70driven chronic immune activation is protective against atherosclerosis," Journal of Innate Immunity, vol. 2, no. 4, pp. 344-352, 2010.

[126] A. Nakajima, H. Oshima, C. Nohara et al., "Involvement of CD70-CD27 interactions in the induction of experimental autoimmune encephalomyelitis," Journal of Neuroimmunology, vol. 109, no. 2, pp. 188-196, 2000.

[127] H. Dai, J. Chen, W. Shao et al., "Blockade of CD27/CD70 pathway to reduce the generation of memory $\mathrm{T}$ cells and markedly prolong the survival of heart allografts in presensitized mice," Transplant Immunology, vol. 24, no. 4, pp. 195202, 2011.

[128] K. Matsumoto, M. Terakawa, K. Miura, S. Fukuda, T. Nakajima, and H. Saito, "Extremely rapid and intense induction of apoptosis in human eosinophils by anti-CD30 antibody treatment in vitro," Journal of Immunology, vol. 172, no. 4, pp. 2186-2193, 2004.

[129] O. Shimozato, K. Takeda, H. Yagita, and K. Okumura, "Expression of CD30 ligand (CD153) on murine activated T cells," Biochemical and Biophysical Research Communications, vol. 256, no. 3, pp. 519-526, 1999.

[130] A. Younes, U. Consoli, S. Zhao et al., "CD30 ligand is expressed on resting normal and malignant human B lymphocytes," British Journal of Haematology, vol. 93, no. 3, pp. 569$571,1996$.

[131] M. A. Bowen, R. K. Lee, G. Miragliotta, S. Y. Nam, and E. R. Podack, "Structure and expression of murine CD30 and its role in cytokine production," Journal of Immunology, vol. 156, no. 2, pp. 442-449, 1996.

[132] H. Harlin, E. Podack, M. Boothby, and M. L. Alegre, "TCR-independent CD30 signaling selectively induces IL13 production via a TNF receptor-associated factor/p38 mitogen-activated protein kinase-dependent mechanism," Journal of Immunology, vol. 169, no. 5, pp. 2451-2459, 2002.

[133] C. A. Smith, H. J. Gruss, T. Davis et al., "CD30 antigen, a marker for Hodgkin's lymphoma, is a receptor whose ligand defines an emerging family of cytokines with homology to TNF," Cell, vol. 73, no. 7, pp. 1349-1360, 1993.

[134] D. N. Mauri, R. Ebner, R. I. Montgomery et al., "LIGHT, a new member of the TNF superfamily, and lymphotoxin $\alpha$ are ligands for herpesvirus entry mediator," Immunity, vol. 8, no. 1, pp. 21-30, 1998.

[135] Y. Morel, J. M. Schiano de Colella, J. Harrop et al., "Reciprocal expression of the TNF family receptor herpes virus entry mediator and its ligand LIGHT on activated T cells: LIGHT down-regulates its own receptor," Journal of Immunology, vol. 165, no. 8, pp. 4397-4404, 2000.

[136] G. Cai and G. J. Freeman, "The CD160, BTLA, LIGHT/ HVEM pathway: a bidirectional switch regulating T-cell activation," Immunological Reviews, vol. 229, no. 1, pp. 244 258, 2009.

[137] Q. Ye, C. C. Fraser, W. Gao et al., "Modulation of LIGHTHVEM costimulation prolongs cardiac allograft survival," Journal of Experimental Medicine, vol. 195, no. 6, pp. 795$800,2002$.

[138] J. A. Harrop, P. C. McDonnell, M. Brigham-Burke et al., "Herpesvirus entry mediator ligand (HVEM-L), a novel ligand for HVEM/TR2, stimulates proliferation of T cells and inhibits HT29 cell growth," Journal of Biological Chemistry, vol. 273, no. 42, pp. 27548-27556, 1998.

[139] F. Kanamaru, P. Youngnak, M. Hashiguchi et al., "Costimulation via glucocorticoid-induced TNF receptor in both conventional and $\mathrm{CD}_{2} 5^{+}$regulatory $\mathrm{CD} 4^{+} \mathrm{T}$ cells," Journal of Immunology, vol. 172, no. 12, pp. 7306-7314, 2004.

[140] B. Kwon, K. Y. Yu, J. Ni et al., "Identification of a novel activation-inducible protein of the tumor necrosis factor receptor superfamily and its ligand," Journal of Biological Chemistry, vol. 274, no. 10, pp. 6056-6061, 1999.

[141] R. S. McHugh, M. J. Whitters, C. A. Piccirillo et al., "CD4 ${ }^{+} \mathrm{CD} 25^{+}$immunoregulatory $\mathrm{T}$ cells: gene expression analysis reveals a functional role for the glucocorticoidinduced TNF receptor," Immunity, vol. 16, no. 2, pp. 311323, 2002.

[142] J. Shimizu, S. Yamazaki, T. Takahashi, Y. Ishida, and S. Sakaguchi, "Stimulation of $\mathrm{CD} 25^{+} \mathrm{CD} 4{ }^{+}$regulatory $\mathrm{T}$ cells through GITR breaks immunological self-tolerance," Nature Immunology, vol. 3, no. 2, pp. 135-142, 2002.

[143] S. Ronchetti, O. Zollo, S. Bruscoli et al., "Frontline: GITR, a member of the TNF receptor superfamily, is costimulatory to mouse T lymphocyte subpopulations," European Journal of Immunology, vol. 34, no. 3, pp. 613-622, 2004.

[144] K. Schneider, K. G. Potter, and C. F. Ware, "Lymphotoxin and LIGHT signaling pathways and target genes," Immunological Reviews, vol. 202, pp. 49-66, 2004.

[145] K. Tamada, K. Shimozaki, A. I. Chapoval et al., "Modulation of T-cell-mediated immunity in tumor and graft-versus-host disease models through the LIGHT costimulatory pathway," Nature Medicine, vol. 6, no. 3, pp. 283-289, 2000.

[146] P. Yu, Y. Lee, W. Liu et al., "Priming of naive T cells inside tumors leads to eradication of established tumors," Nature Immunology, vol. 5, no. 2, pp. 141-149, 2004.

[147] C. Kurts, F. R. Carbone, M. F. Krummel, K. M. Koch, J. F. A. P. Miller, and W. R. Heath, "Signalling through CD30 protects against autoimmune diabetes mediated by CD8 T cells," Nature, vol. 398, no. 6725, pp. 341-344, 1999.

[148] W. J. Sandberg, B. Halvorsen, A. Yndestad et al., "Inflammatory interaction between LIGHT and proteinase-activated receptor-2 in endothelial cells: potential role in atherogenesis," Circulation Research, vol. 104, no. 1, pp. 60-68, 2009.

[149] W. H. Lee, S. H. Kim, Y. Lee et al., "Tumor necrosis factor receptor superfamily 14 is involved in atherogenesis by inducing proinflammatory cytokines and matrix metalloproteinases," Arteriosclerosis, Thrombosis, and Vascular Biology, vol. 21, no. 12, pp. 2004-2010, 2001.

[150] H. Scholz, W. Sandberg, J. K. Damås et al., "Enhanced plasma levels of LIGHT in unstable angina: possible pathogenic role in foam cell formation and thrombosis," Circulation, vol. 112, no. 14, pp. 2121-2129, 2005.

[151] G. Z. Liu, L. B. Fang, P. Hjelmstrom, and X. G. Gao, "Enhanced plasma levels of LIGHT in patients with acute atherothrombotic stroke," Acta Neurologica Scandinavica, vol. 118, no. 4, pp. 256-259, 2008.

[152] W. J. Kim, E. M. Bae, Y. J. Kang et al., "Glucocorticoidinduced tumour necrosis factor receptor family related protein (GITR) mediates inflammatory activation of macrophages that can destabilize atherosclerotic plaques," Immunology, vol. 119, no. 3, pp. 421-429, 2006.

[153] O. J. de Boer, J. J. van der Meer, P. Teeling, C. M. van der Loos, and A. C. van der Wal, "Low numbers of FOXP3 positive regulatory $\mathrm{T}$ cells are present in all developmental stages of human atherosclerotic lesions," PLoS One, vol. 2, no. 8, article e779, 2007.

[154] Y. Y. Wang, P. Zhang, Y. F. Liu, and G. H. Cheng, "TRAF-mediated regulation of immune and inflammatory responses," Science China Life Sciences, vol. 53, no. 2, pp. 159$168,2010$. 
[155] A. Zirlik, U. Bavendiek, P. Libby et al., "TRAF-1, -2, -3, 5 , and -6 are induced in atherosclerotic plaques and differentially mediate proinflammatory functions of CD40L in endothelial cells," Arteriosclerosis, Thrombosis, and Vascular Biology, vol. 27, no. 5, pp. 1101-1107, 2007.

[156] A. Missiou, N. Köstlin, N. Varo et al., "Tumor necrosis factor receptor-associated factor 1 (TRAF1) deficiency attenuates atherosclerosis in mice by impairing monocyte recruitment to the vessel wall," Circulation, vol. 121, no. 18, pp. 20332044, 2010.

[157] A. Missiou, P. Rudolf, P. Stachon et al., "TRAF5 deficiency accelerates atherogenesis in mice by increasing inflammatory cell recruitment and foam cell formation," Circulation Research, vol. 107, no. 6, pp. 757-766, 2010.

[158] E. Lutgens, D. Lievens, L. Beckers et al., "Deficient CD40TRAF6 signaling in leukocytes prevents atherosclerosis by skewing the immune response toward an antiinflammatory profile," Journal of Experimental Medicine, vol. 207, no. 2, pp. 391-404, 2010.

[159] P. Stachon, A. Missiou, C. Walter et al., "Tumor necrosis factor receptor associated factor 6 is not required for atherogenesis in mice and does not associate with atherosclerosis in humans," PLoS One, vol. 5, no. 7, Article ID e11589, 2010.

[160] C. Nohara, H. Akiba, A. Nakajima et al., "Amelioration of experimental autoimmune encephalomyelitis with anti-OX40 ligand monoclonal antibody: a critical role for OX40 ligand in migration, but not development, of pathogenic T cells," Journal of Immunology, vol. 166, no. 3, pp. 2108-2115, 2001.

[161] G. Zheng, B. Wang, and A. Chen, "The 4-1BB costimulation augments the proliferation of $\mathrm{CD} 4^{+} \mathrm{CD} 25^{+}$regulatory $\mathrm{T}$ cells," Journal of Immunology, vol. 173, no. 4, pp. 2428-2434, 2004.

[162] A. Kroemer, X. Xiao, M. D. Vu et al., "OX40 controls functionally different $\mathrm{T}$ cell subsets and their resistance to depletion therapy," Journal of Immunology, vol. 179, no. 8, pp. 5584-5591, 2007.

[163] L. Myers, C. Takahashi, R. S. Mittler, R. J. Rossi, and A. T. Vella, "Effector CD8 T cells possess suppressor function after 4-1BB and Toll-like receptor triggering," Proceedings of the National Academy of Sciences of the United States of America, vol. 100, no. 9, pp. 5348-5353, 2003.

[164] K. Sugamura, N. Ishii, and A. D. Weinberg, "Therapeutic targeting of the effector T-cell costimulatory molecule OX40," Nature Reviews Immunology, vol. 4, no. 6, pp. 420-431, 2004.

[165] L. M. Higgins, S. A. C. McDonald, N. Whittle, N. Crockett, J. G. Shields, and T. T. MacDonald, "Regulation of T cell activation in vitro and in vivo by targeting the OX40-OX40 ligand interaction: amelioration of ongoing inflammatory bowel disease with an OX40-IgG fusion protein, but not with an OX40 ligand-IgG fusion protein," Journal of Immunology, vol. 162, no. 1, pp. 486-493, 1999.

[166] E. Stuber, A. Von Freier, D. Marinescu, and U. R. Folsch, "Involvement of OX40-OX401 interactions in the intestinal manifestations of the murine acute graft-versus-host disease," Gastroenterology, vol. 115, no. 5, pp. 1205-1215, 1998.

[167] A. D. Weinberg, D. N. Bourdette, T. J. Sullivan et al., "Selective depletion of myelin-reactive $\mathrm{T}$ cells with the anti-OX40 antibody ameliorates autoimmune encephalomyelitis," Nature Medicine, vol. 2, no. 2, pp. 183-189, 1996.

[168] A. D. Weinberg, K. W. Wegmann, C. Funatake, and R. $\mathrm{H}$. Whitham, "Blocking OX-40/OX-40 ligand interaction in vitro and in vivo leads to decreased $\mathrm{T}$ cell function and amelioration of experimental allergic encephalomyelitis," Journal of Immunology, vol. 162, no. 3, pp. 1818-1826, 1999.
[169] J. Lee, E. N. Lee, E. Y. Kim et al., "Administration of agonistic anti-4-1BB monoclonal antibody leads to the amelioration of inflammatory bowel disease," Immunology Letters, vol. 101, no. 2, pp. 210-216, 2005.

[170] M. Mahmoudi, M. Hedayat, N. Rezaei, A. Saboor-Yaraghi, and M. Mahmoudi, "In vitro soluble CD30 levels in patients with chronic stable coronary artery disease," Iranian Journal of Allergy, Asthma and Immunology. In press. 


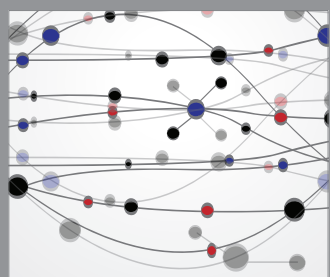

The Scientific World Journal
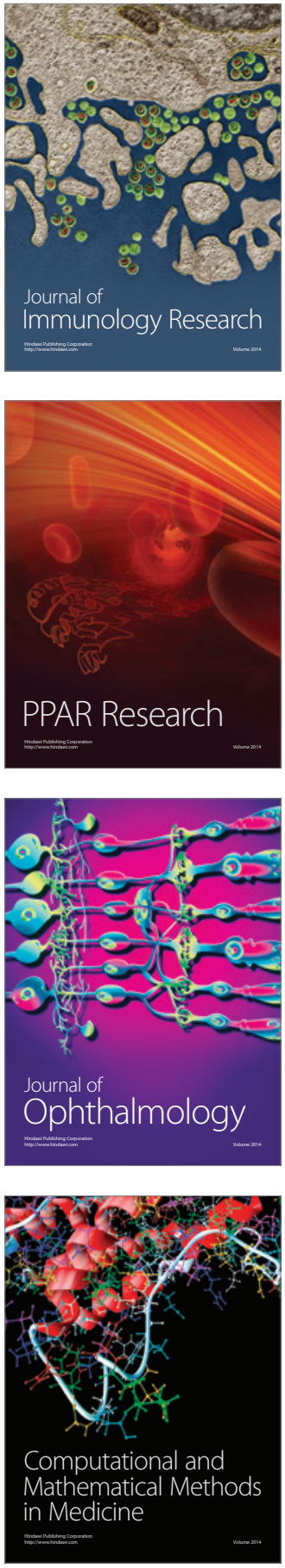

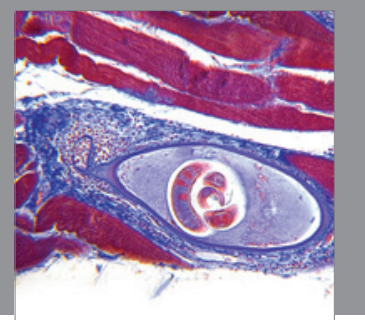

Gastroenterology

Research and Practice
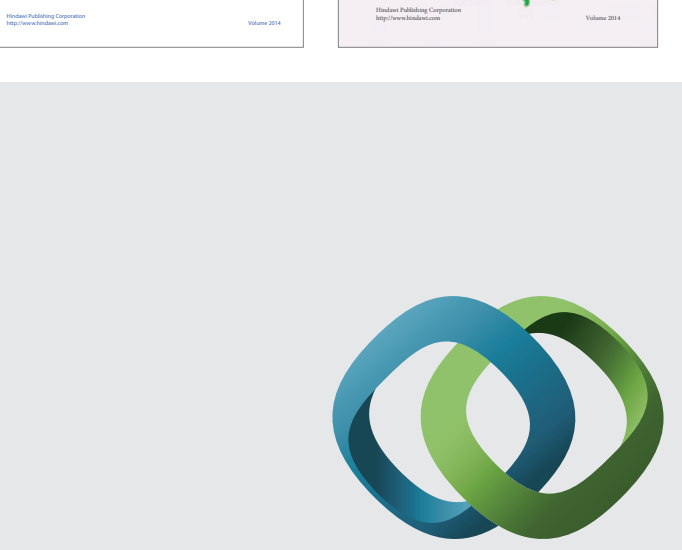

\section{Hindawi}

Submit your manuscripts at

http://www.hindawi.com
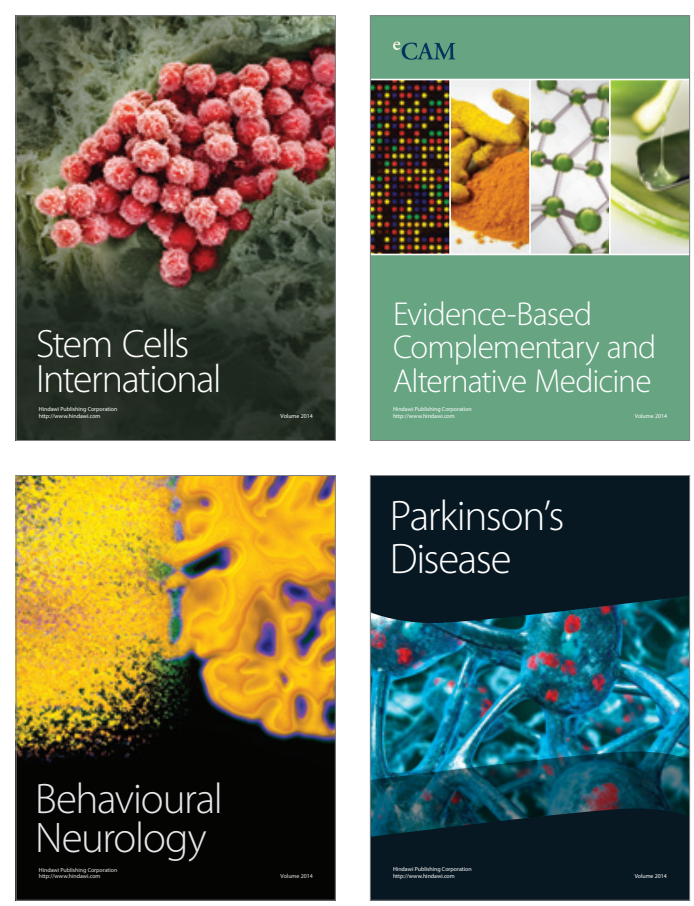

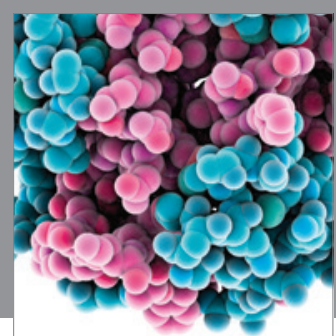

Journal of
Diabetes Research

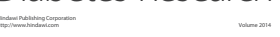

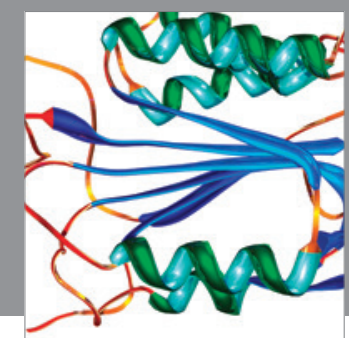

Disease Markers
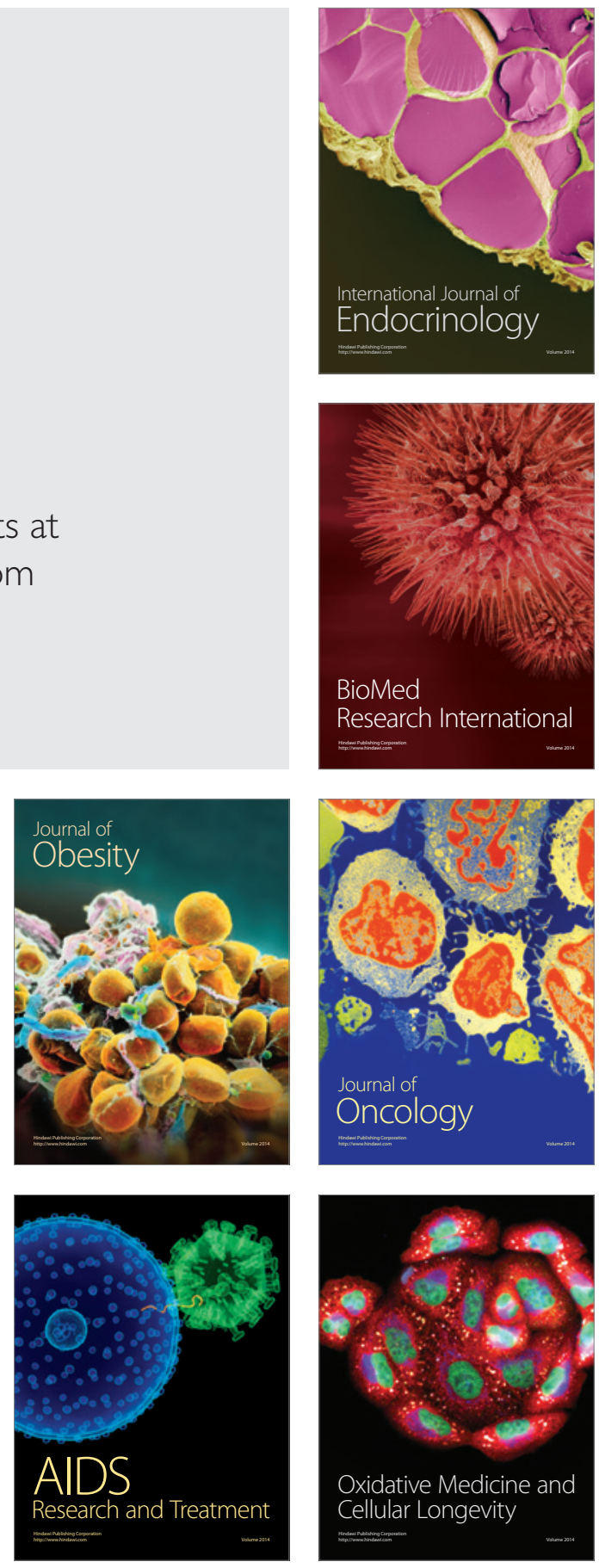